\title{
CDRD and PNPR satellite passive microwave precipitation retrieval algorithms: EuroTRMM/EURAINSAT origins and H-SAF operations
}

\author{
A. Mugnai ${ }^{1}$, E. A. Smith ${ }^{2}$, G. J. Tripoli ${ }^{3}$, B. Bizzarri ${ }^{4}$, D. Casella ${ }^{1}$, S. Dietrich ${ }^{1}$, F. Di Paola ${ }^{5}$, G. Panegrossi ${ }^{1}$, and \\ P. Sanò ${ }^{1}$ \\ ${ }^{1}$ Institute of Atmospheric Sciences and Climate (ISAC), Italian National Research Council (CNR), Rome, Italy \\ ${ }^{2}$ Center for Research on the Changing Earth System (CRCES), (HQ: Catonsville, Maryland, USA), Tallahassee, Florida, USA \\ ${ }^{3}$ Dept. of Atmospheric and Oceanic Sciences (AOS), University of Wisconsin, Madison, Wisconsin, USA \\ ${ }^{4}$ World Meteorological Organization (WMO) Consultant, Rome, Italy \\ ${ }^{5}$ Institute of Methodologies for Environmental Analysis (IMAA), Italian National Research Council (CNR), \\ Tito Scalo (PZ), Italy
}

Correspondence to: A. Mugnai (alberto.mugnai@artov.isac.cnr.it)

Received: 4 November 2012 - Published in Nat. Hazards Earth Syst. Sci. Discuss.: -

Revised: 11 February 2013 - Accepted: 18 February 2013 - Published: 10 April 2013

\begin{abstract}
Satellite Application Facility on Support to Operational Hydrology and Water Management (H-SAF) is a EUMETSAT (European Organisation for the Exploitation of Meteorological Satellites) program, designed to deliver satellite products of hydrological interest (precipitation, soil moisture and snow parameters) over the European and Mediterranean region to research and operations users worldwide. Six satellite precipitation algorithms and concomitant precipitation products are the responsibility of various agencies in Italy. Two of these algorithms have been designed for maximum accuracy by restricting their inputs to measurements from conical and cross-track scanning passive microwave (PMW) radiometers mounted on various low Earth orbiting satellites. They have been developed at the Italian National Research Council/Institute of Atmospheric Sciences and Climate in Rome (CNR/ISAC-Rome), and are providing operational retrievals of surface rain rate and its phase properties. Each of these algorithms is physically based, however, the first of these, referred to as the Cloud Dynamics and Radiation Database (CDRD) algorithm, uses a Bayesianbased solution solver, while the second, referred to as the PMW Neural-net Precipitation Retrieval (PNPR) algorithm, uses a neural network-based solution solver. Herein we first provide an overview of the two initial EU research and applications programs that motivated their initial development,
\end{abstract}

EuroTRMM and EURAINSAT (European Satellite Rainfall Analysis and Monitoring at the Geostationary Scale), and the current H-SAF program that provides the framework for their operational use and continued development. We stress the relevance of the CDRD and PNPR algorithms and their precipitation products in helping secure the goals of H-SAF's scientific and operations agenda, the former helpful as a secondary calibration reference to other algorithms in H-SAF's complete mix of algorithms. Descriptions of the algorithms' designs are provided including a few examples of their performance. This aspect of the development of the two algorithms is placed in the context of what we refer to as the TRMM era, which is the era denoting the active and ongoing period of the Tropical Rainfall Measuring Mission (TRMM) that helped inspire their original development. In 2015, the ISAC-Rome precipitation algorithms will undergo a transformation beginning with the upcoming Global Precipitation Measurement (GPM) mission, particularly the GPM Core Satellite technologies. A few years afterward, the first pair of imaging and sounding Meteosat Third Generation (MTG) satellites will be launched, providing additional technological advances. Various of the opportunities presented by the GPM Core and MTG satellites for improving the current CDRD and PNPR precipitation retrieval algorithms, as well as extending their product capability, are discussed. 


\section{Introduction}

Since the introduction of the Satellite Application Facility on Support to Operational Hydrology and Water Management (H-SAF) in 2005 (see Bizzarri et al., 2005; Mugnai et al., 2006), the Italian National Research Council/Institute of Atmospheric Sciences and Climate in Rome (CNR/ISACRome) has developed two of the official H-SAF satellite precipitation retrieval algorithms. (A total of six such algorithms are underway at various Italian institutions; Bizzarri et al., 2008 and Mugnai et al., 2013.) The two ISAC-Rome algorithms provide retrievals of surface precipitation and its phase properties from conically and cross-track scanning passive microwave (PMW) radiometers mounted on available low Earth orbiting (LEO) satellites. Both algorithms are physically based although they differ in their use of the retrieval solution solvers. The first is referred to as the Cloud Dynamics and Radiation Database (CDRD) algorithm - it is based on a Bayesian solution solver. This approach is appropriate for applications with measurements from conically scanning radiometers in which the atmospheric path is held invariant across the scan passage, and thus the instantaneous field-of-view (IFOV) of a given channel is held constant. The second is referred to as the PMW Neural-net Precipitation Retrieval (PNPR) algorithm - it is based on a neural network solution solver. This approach is appropriate for applications with measurements from cross-track scanning radiometers in which the atmospheric path is changing across the scan passage, and thus so are the IFOVs.

The main intent behind the CDRD and PNPR algorithms is, by restricting inputs to only PMW measurements, to produce the most accurate estimates of satellite rainfall possible, given the available PMW radiometers flying over the European and Mediterranean region. In so doing, they are helpful as secondary calibration reference algorithms to the other $\mathrm{H}$ SAF precipitation algorithms, in which three of the others combine PMW radiometer measurements with infrared (IR) measurements obtained from geostationary (GEO) satellites, typically Meteosat Second Generation (MSG) satellites. The advantage of the combined algorithms is that they provide retrievals continuously every MSG Earth scan (15 or $30 \mathrm{~min}$ ), their disadvantage being that IR measurements are insensitive to the presence of rainfall, meaning the algorithms depend on the correlation of cloudiness with rainfall with statistical linkage to PMW estimates only available twice per day for any given sun-synchronous satellite platform. Herein we describe the CDRD and PNPR algorithms and a few examples of their performance, all within the context of their historical development.

The PMW measurements for H-SAF are obtained from a collection of radiometers on US and EUMETSAT (European Organisation for the Exploitation of Meteorological Satellites) satellites. These consist of: (1) the Special Sensor Microwave Imager (SSM/I) and (2) Special Sensor Microwave Imager-Sounder (SSMIS) conical scanners flown on US Dept. of Defense (DOD) Defense Military Satellite Program (DMSP) satellites; and (3) the Advanced Microwave Sounding Unit A (AMSU-A) in tandem with (4) the Microwave Humidity Sounder (MHS) cross-track scanners flown on US Dept. of Commerce (DOC) National Oceanic and Atmospheric Administration (NOAA) Polar Orbiting Environmental Satellites (POESs), referred to as NOAA-18 and NOAA-19, and EUMETSAT's two Meteorological Operational satellites METOP-A/B. All such satellites are LEOs in sun-synchronous over-the-pole orbits.

The development and progress of the CDRD and PNPR algorithms has taken place during what we refer to as the TRMM era, which is the era denoting the active and ongoing period of the Tropical Rainfall Measuring Mission (TRMM) and its underlying experiment to understand precipitation in weather and climate (see Simpson et al., 1996 for TRMM background information). As of now, the term TRMM actually describes a period of history as well as a particular satellite mission. The TRMM mission and experiment, originally consisting of a joint agreement and research program between the US and Japanese space agencies to launch the 5-instrument TRMM observatory and analyze its data, was the mission that propelled the measurement of rainfall from space into the 21st century with modern instruments and up-to-date high quality rainfall retrieval algorithms. In turn, the mission motivated and triggered a number of research and operational programs worldwide to place greater emphasis on hydrological remote sensing and use of retrieved hydrological products in data assimilation and weather/climate prediction. Three such proactive programs were developed within the European Union (EU), introduced in the next two paragraphs and described with overviews in Sect. 2.

In 1998, not too long after the launch of the TRMM satellite in November 1997, a program was formed within the EU called EuroTRMM, supported by both the European Commission (EC) and the European Space Agency (ESA); see ECMWF (2001). This program was designed to enable EU remote sensing specialists and their colleagues in related areas to contribute to the TRMM experiment, and by doing so, assist the EU with their own problem solving involving new research and applications in the areas of satellite precipitation retrieval, hydrological model development and especially weather forecast model data assimilation. After the EuroTRMM program matured, and had motivated a turn within the EU to seize better advantage of measurements produced by PMW radiometers being flown, or to be flown, on a number of research and operational satellites by American, European and Japanese space agencies, a 2nd applications oriented precipitation-centric program was created by the EC in 2001, designed to use both LEO and GEO satellites for acquisition of rainfall and related information. This was the European Satellite Rainfall Analysis and Monitoring at the Geostationary Scale (EURAINSAT) program; see Levizzani et al. (2007). 
The EuroTRMM and EURAINSAT research and applications programs rapidly galvanized a growing community of precipitation remote sensing specialists, hydrological modeling specialists and data assimilation specialists, as well as specialists in other areas involving precipitation measuring by rain gauges and radar sets, ground validation $(\mathrm{GV})$ analysis, and mathematical/statistical problem solving essential for geophysical modeling and data assimilation. This community, in turn, became the origin of scientific expertise that helped evolve the formation of the H-SAF. In fact, it was during the EuroTRMM and EURAINSAT programs that the CDRD and PNPR algorithms began. The H-SAF program now represents the past, present and future in the use of hydrological retrieval products from space across the EU - for research, for applications and for operations. It has been the outcome of a remarkable process of scientist dedication and scientific networking that can take a novel scientific incentive and produce a creative scientific application across an entire continental sphere and beyond. To help understand this process, see Mugnai et al. (2013) for an account of the H-SAF precipitation products program and the range of its participating institutions.

In the course of the next three years, the current ISACRome precipitation algorithms, which are described in Sect. 3, will greatly mature. In the 2015 time frame, a new era will begin, the era of the Global Precipitation Measurement (GPM) mission, which is described in Sect. 4. This new mission has been designed as a constellation of satellites involving six to ten research and operational members, depending on the time frame. These constellation members will be referenced to what is called the GPM Core Satellite, an observatory that will carry an advanced Dual-frequency Precipitation Radar (DPR) system and an advanced multichannel PMW radiometer referred to as the GPM Microwave Imager (GMI). Accordingly, the CDRD and PNPR algorithms will begin a transformation over to the newer era, the newer space platforms, the newer instrument technologies and the newer measurements. Not too many years afterward, the first pair of imaging and sounding Meteosat Third Generation (MTG) satellites will be launched (i.e., sometime in the 2017-2019 time frame). These GEO platforms will provide additional advances that will be seized upon by the community of hydrological remote sensing scientists, including those at ISAC-Rome. A number of new opportunities will be presented by the GPM mission and MTG satellites for improving the current CDRD and PNPR retrieval algorithms, as well as extending their product capability.

\section{Overviews of EuroTRMM, EURAINSAT and H-SAF programs}

\subsection{EuroTRMM program}

The EuroTRMM program was initiated in February 1998 after planning meetings between a group of European and American scientists. ${ }^{1}$ The meetings concerned the means to involve the EC and the European Space Agency (ESA) with TRMM research and how to identify and form a science team of EU specialists in remote sensing, precipitation retrieval, hydrological modeling and data assimilation. It was deemed important that the team's collective research skills would resonate with the goals of the TRMM experiment and the rapidly developing requirements in the EU for better precipitation retrieval products and better methods to entrain these data into new hydrological models and data assimilation systems under development at the EU's operational weather forecast centers. Following the initial meetings and through the efforts of the main founders, the EC and ESA supported this program over 1998-2003.

Two of the overriding objectives of the EuroTRMM program were to develop a set of physical and statistical precipitation retrieval algorithms that could be analyzed for comparison and contrast, and to place much greater emphasis on PMW channel brightness temperature (TB) observation errors and forward model error characteristics, than was being given to these issues by the Japanese and US TRMM science teams. (Note in this context, forward models essentially referred to the radiative transfer equation (RTE) models needed by the physically-based precipitation retrieval algorithms to relate hydrometeor information along the radiometer measurement paths to observed TBs - denoting the physical algorithms intrinsically involved an inversion process.) This research was needed to address one of the fundamental needs of data assimilation systems being used at the operational weather forecast centers, such as the European Centre for Medium-Range Weather Forecasts (ECMWF). In essence, before the required error covariance matrices in the data assimilation systems could be defined to enable the assimilation of the newer satellite precipitation data, the errors and their covariant relationships stemming from both the radiometers and the forward models needed to be thoroughly understood and defined. This was the type of research that was needed to make improved precipitation retrievals relevant to weather forecasting (see ECMWF, 2001). As part of this research, it was also decided to develop a better heritage for the forward models (e.g., see Smith et al., 2002).

An important outcome of the EuroTRMM research program was to look beyond the PMW measurements them-

\footnotetext{
${ }^{1}$ A. Mugnai (CNR/Institute of Atmospheric Physics - at the time) and E. A. Smith (Florida State University - at the time) were main participants in this group, which was led by Pedro Poiares Baptista (ESA-ESTEC) and Jacques Testud (CNRS/Centre for Terrestrial and Planetary Studies - at the time).
} 
selves, and begin experimenting with how alternative meteorological parameters coming from the cloud resolving models that were being used to underpin various physical retrieval algorithms (i.e., dynamical, thermodynamical and hydrological prognostic and diagnostic model variables) could be used to aid the retrieval solvers. In fact, it was this type of methodology that later evolved into the CDRD Bayesian algorithm, designed for use with conical-scan radiometer measurements. EuroTRMM also placed emphasis on developing better GV networks and extending the use of PMW measurements for retrieval of snowfall, recognizing that both of these topics required considerable time periods to complete the necessary research.

\subsection{EURAINSAT program}

In 2001, as part of the 5th Framework program for European research and technological development, the EC founded the EURAINSAT program to place greater emphasis on how GEO satellite data could be better applied for retrieval of precipitation at GEO spatiotemporal scales. Various of EURAINSAT's participating research groups had already recognized that time-lapse IR images from GEO platforms provided "practically useful" information in conjunction with the PMW measurements. Also, various Japanese and US groups within the joint TRMM science team had recognized the possibilities for combining LEO-PMW and GEOIR measurements for continuous precipitation information, although it was also recognized that this type of combined algorithm was vulnerable to greater uncertainties than the PMW-only type algorithms. It was obvious at the time, that more research was needed.

In the course of the next five years, a number of combination PMW-IR algorithms evolved and matured in Europe, Japan and the US. Descriptions of most of these schemes can be found in the EURAINSAT book (Levizzani et al., 2007). The algorithm methodologies can be divided into blending schemes and morphing schemes. In blending schemes (e.g., Levizzani et al., 1996; Turk et al., 1999; Sorooshian et al., 2000; Marzano et al., 2004; Turk and Miller, 2005; Huffman et al., 2007; Torricella et al., 2007), the first few statistical moments of spatially aligned PMW and IR measurement probability distribution functions (pdfs) from coincident data segments are matched so that the recoverable PMW pdf rain rates can be directly assigned to the associated adorned IR pdf TBs, thus producing an IR-based "direct" rain rate pdf but only limited to the coincidence times (twice per day for any sun-synchronous LEO satellite or more for the non-sunsynchronous TRMM satellite). In intervening times when only GEO IR data are available, the nearest-in-time moment matching factors (pdf transform factors) are used to transform unadorned IR pdf TBs to an IR-based "indirect" rain rate pdf. Thus by compiling multiple data segments making up overpasses, it is possible to provide rough approximations of rainfall at the GEO imaging rate (15 or $30 \mathrm{~min}$ ), through- out the course of a day. The term rough is emphasized because the equivalences forced between the PMW and IR pdfs do not provide guarantees that the IR-based rain rates are actually equivalent to the PMW-derived rain rates when taken one measurement at a time.

The morphing technique (e.g., Grose et al., 2002; Joyce et al., 2004; Wimmers and Velden, 2007) is more sophisticated than blending, although it also suffers from the basic physics-driven uncertainties that precipitation is not actually detected at IR wavelengths. In morphing, semi-continuous GEO IR images between two PMW overpasses are used to produce position velocity vectors and IR-TB tendency vectors that serve as linear (or if allowed, nonlinear) interpolation factors that are used to create synthetic PMW images at all GEO IR image times. A PMW-only retrieval algorithm is then applied to the synthetic image sequence. Morphing has distinct advantages over blending, but not complete superiority (Ebert et al., 2007). Notably, the H-SAF program supports both a blending algorithm and a morphing algorithm, provided by ISAC-Bologna, as further sources for the H-SAF precipitation product mix.

Among other goals, EURAINSAT considered research problems pertaining to: (a) technique development in GV, (b) simple methods to use both visible wavelength and IR measurements to approximate cloud-top microphysics and aerosol effects on precipitation, (c) methodologies to use lightning data to better understand precipitation, particularly convective precipitation and the formation of large ice hydrometeors, and (d) experimentation with neural networks to seek alternatives to algebraic inversion, relaxation, optimal estimation, Bayesian or regression solvers in physical and/or statistical retrieval algorithms. In fact, it was the latter focus area that led to the development of the second of the ISACRome retrieval schemes, i.e., the PNPR algorithm, designed for use with PMW cross-track scanners.

\subsection{H-SAF program}

Within the EU, EUMETSAT is the agency responsible for managing operational meteorological satellites (top portion of Fig. 1). EUMETSAT's application ground segments are divided into a centralized facility at its headquarters in Darmstadt, Germany, and a number of decentralized facilities distributed as consortia made up by EUMETSAT member states. The consortia are referred to as Satellite Application Facilities (SAFs). Eight SAFs are now in place, which include the H-SAF (Hydrology SAF) developed in 2005 to support hydrology operations and research (bottom portion of Fig. 1); see Bizzarri et al. (2005). There are two web sites which provide detailed information concerning H-SAF. ${ }^{2}$ The development of the Hydrology SAF was a response to a

\footnotetext{
2 See two URLs: (1) www.eumetsat.int/Home/Main/Satellites/ GroundNetwork/ApplicationGroundSegment/SAFs/SAFProjects/ SP_2010061112220732 and (2) hsaf.meteoam.it (registration required for second site).
} 


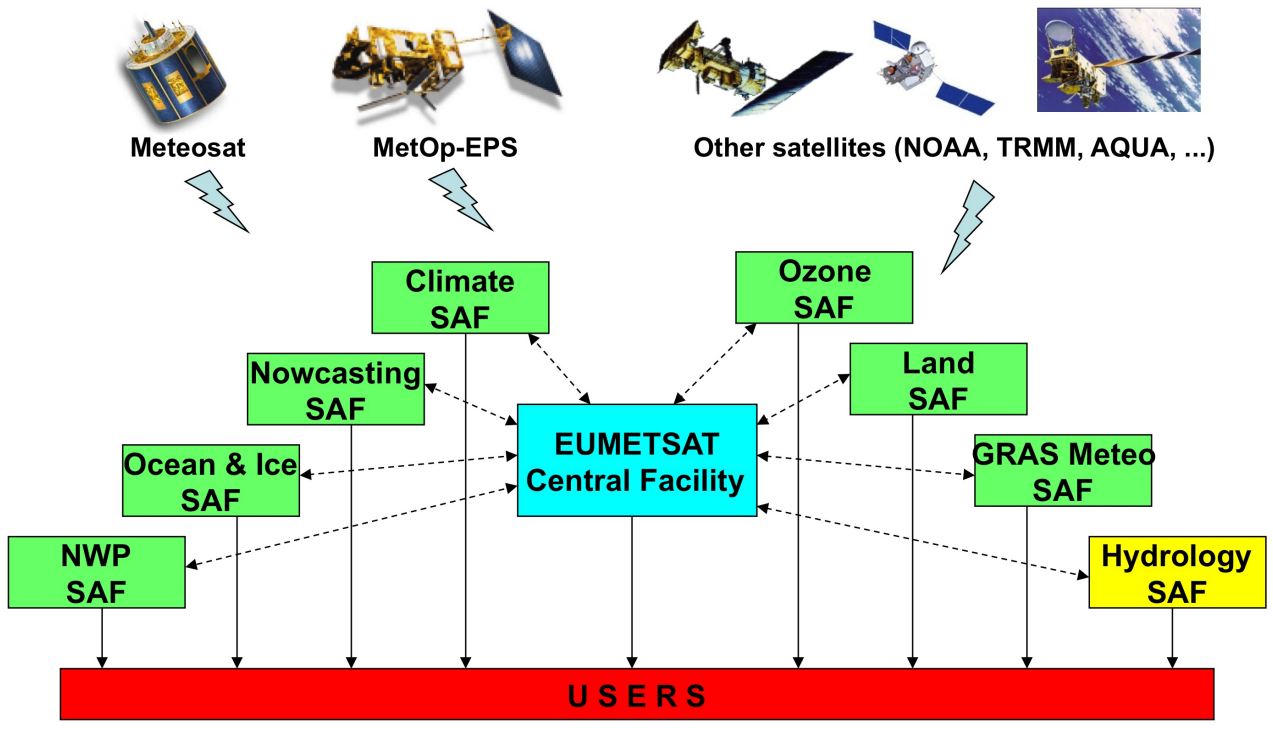

Fig. 1. Above are elements of EUMETSAT's satellite applications facilities, while below are elements of EUMETSAT's decentralized applications ground segment.

growing interest within the EU to the steadily improving: (a) quality of operational and research satellite data, (b) capabilities in hydrological remote sensing science, (c) performances of hydrological models and the hydrological components of weather and climate prediction models and (d) techniques for assimilating hydrological observations into prediction models, particularly satellite retrieval observations. Table 1 provides a summary of the institutional composition of H-SAF consortium by country. It is evident that the $\mathrm{H}-\mathrm{SAF}$ program has caught on aggressively across the EU. (Note that although the ECMWF is not a country, it is considered a separate entity within the H-SAF consortium and thus is included in the summary.)

The objectives of the H-SAF are threefold. First, H-SAF is to provide for new satellite-derived products from existing and future satellites, with sufficient time and space resolution to satisfy the needs of operational hydrology, and focused on three areas of hydrological retrieval: (1) rainfall (rates, accumulation, phase), (2) snowfall (cover, melt-state, water-equivalent) and (3) soil moisture (near-surface, rootlayers). Second, H-SAF is to underwrite the capability to perform independent $\mathrm{GV}$ of the usefulness of the new products for mitigating against damage due to floods, landslides and avalanches, and in evaluating water resources, including the activities of (1) downscaling/upscaling modeling from observed and predicted fields to basin level, (2) fusion of satellite-derived measurements with data from radar and rain gauge networks, (3) assimilation of satellite-derived products in hydrological models for model performance evaluation, and (4) assessment of the impact of the new satellite-derived products on the spectrum of hydrological applications. Third, $\mathrm{H}-\mathrm{SAF}$ is to provide a central data distribution facility which offers a straightforward and effective means for public access to the new satellite precipitation products. This activity is being conducted by the Centro Nazionale di Meteorologia e Climatologia Aeronautica (CNMCA) of the Italian Air Force in Pratica di Mare (near Rome, Italy) which also serves as the H-SAF host institute.

The H-SAF GV network for precipitation measurements is extensive. It includes approximately 4575 rain gauges distributed throughout seven countries including the non-EU nation state of Turkey, and an 81-site C-band and Ka-band radar network distributed over Western and Eastern Europe also including Turkey (Puca et al., 2013). Notably, the H-SAF GV network is the most extensive of its kind in the world, and will possibly become the greatest resource to the GPM mission for wide area $\mathrm{GV}$ of its rainfall retrieval products.

\section{ISAC-Rome's H-SAF PMW precipitation algorithms in TRMM era}

It is a tautology that a collection of different methodologies to solve the same problem would be better off if one such methodology could serve as a calibration reference to all others in gauging the performance of the individual members of the collection. One of the oddities of satellite precipitation retrieval algorithms over past decades is that the community of scientists involved in their development has never agreed on a calibration reference algorithm, although it is fair to say that the TRMM experiment has made some progress along those lines with the facility TRMM Precipitation Radar (PR) algorithm 2a25-v7 (Iguchi et al., 2000, 2009) and the Combined PR - TRMM Microwave Imager (TMI) algorithm 2b31-v7 (Marzano et al., 1994, 1999; Farrar, 1997; Haddad et al., 
Table 1. Institutional composition of H-SAF Consortium by country. (Note ECMWF is not a country, but is shown in country column because it is an $\mathrm{H}-\mathrm{SAF}$ consortium entity.)

\begin{tabular}{|c|c|}
\hline Country & $\begin{array}{l}\text { Contributing Institutions } \\
\text { (responsible unit in bold) }\end{array}$ \\
\hline Austria & $\begin{array}{l}\text { Zentral Anstalt für Meteorologie und Geodynamik } \\
\text { Technische Univ. Wien, Inst. Photogrammetrie \& Fernerkundung }\end{array}$ \\
\hline Belgium & Institut Royal Météorologique \\
\hline Bulgaria & National Institute of Meteorology and Hydrology \\
\hline ECMWF & European Centre for Medium-Range Weather Forecasts \\
\hline Finland & $\begin{array}{l}\text { Finnish Meteorological Institute } \\
\text { Helsinki Technical University, Laboratory of Space Technology } \\
\text { Finnish Environment Institute }\end{array}$ \\
\hline France & $\begin{array}{l}\text { Météo-France } \\
\text { CNRS Centre d'Etudes Spatiales de la BIOsphere } \\
\text { CNRS Centre d'études des Environnements Terrestre et Planétaires }\end{array}$ \\
\hline Germany & Bundesanstalt für Gewässerkunde \\
\hline Hungary & Hungarian Meteorological Service \\
\hline Italy & $\begin{array}{l}\text { Servizio Meteorologico dell'Aeronautica } \\
\text { Dipartimento Protezione Civile, Presidenza Consiglio Ministri } \\
\text { CNR Istituto di Scienze dell'Atmosfera e del Clima (Bologna \& Rome units) } \\
\text { Università di Ferrara, Dipartimento di Fisica }\end{array}$ \\
\hline Poland & Institute of Meteorology and Water Management \\
\hline Slovakia & Slovenský Hydrometeorologický Ústav \\
\hline Turkey & $\begin{array}{l}\text { Turkish State Meteorological Service } \\
\text { Middle East Technical University, Civil Engineering Department } \\
\text { Istanbul Technical University, Meteorological Department } \\
\text { Anadolu University }\end{array}$ \\
\hline
\end{tabular}

1997; Smith et al., 1997). These two algorithms have often invited other algorithm developers, particularly those based on PMW radiometer measurements alone, to gauge the performance of their algorithms against the two facility algorithms, which have the advantage of using data based on active power radar signals.

As discussed in Sect. 3.1.4, we have done just that for a year of data within the region for which the CDRD database has been designed to apply, that is the European/Mediterranean Basin region. As will be discussed, we obtain nearly equivalent performance over water surfaces but significantly better performance for land surfaces relative to the TRMM TMI algorithm, i.e., TRMM facility algorithm 2a12-v7 (Kummerow et al., 2011; Munchak and Kummerow, 2011), when using the TRMM PR 2a25-v7 algorithm as the reference. This provides additional insight in understanding why we stated earlier in the paper that the CDRD algorithm would be the more accurate of the set of H-SAF precipitation algorithms. Moreover, it provides an incentive to use the CDRD algorithm as a secondary calibration standard for the H-SAF mix.

\subsection{Cloud Dynamics and Radiation Database (CDRD) algorithm}

Table 2 provides a brief summary of the attributes of the CDRD and PNPR algorithms, including descriptors pertaining to the official $\mathrm{H}-\mathrm{SAF}$ algorithm version codes, $\mathrm{H}-\mathrm{SAF}$ algorithm names, ISAC-Rome algorithm names, products and data sources, methodologies and finally the current status of each algorithm in terms of H-SAF nomenclature. The PR-OBS-1 algorithm represents a modified and improved methodology applied to the now conventional Cloud Radiation Database (CRD) methodology originally developed by Smith et al. (1992, 1994a, b) and Mugnai et al. (1993), and applied repeatedly since that time, e.g., see Pierdicca et al. (1996), Bauer et al. (2000, 2001, 2005), Kummerow et al. (2001), Chen and Staelin (2003), Di Michele et al. (2003, 2005), Tassa et al. (2003, 2006), Grecu et al. (2004), Mugnai et al. (2008) and Surussavadee and Staelin (2008a, b) as cases in point. In physical terms, the new methodology is referred to as a Cloud Dynamics and Radiation Database (CDRD) algorithm; see the series of papers by Sanò et al. (2013), Casella et al. (2013) and Smith et al. (2013) which explain 
Table 2. Summary of two CNR/ISAC-Rome PMW satellite algorithm attributes, which includes official H-SAF algorithm version codes, $\mathrm{H}-\mathrm{SAF}$ algorithm names, ISAC-Rome algorithm names, products and data sources, methodologies and current statuses. (All Italian H-SAF satellite precipitation products are routinely generated at Centro Nazionale di Meteorologia e Climatologia Aeronautica (CNMCA), which also manages associated precipitation product data services for H-SAF user community.)

\begin{tabular}{|c|c|c|c|c|c|}
\hline $\begin{array}{l}\text { Algorithm } \\
\text { Version Code }\end{array}$ & $\begin{array}{l}\text { H-SAF } \\
\text { Name }\end{array}$ & $\begin{array}{l}\text { ISAC-Rome } \\
\text { Name }\end{array}$ & $\begin{array}{l}\text { Algorithm Product Description } \\
\text { (Satellite/Model Data Sources) }\end{array}$ & $\begin{array}{l}\text { Algorithm } \\
\text { Methodology }\end{array}$ & $\begin{array}{l}\text { Current } \\
\text { Status }\end{array}$ \\
\hline $\mathrm{H}-01$ & PR-OBS-1 & CDRD & $\begin{array}{l}\text { Precipitation Rate at Surface with Indication of Phase } \\
\text { (LEO/PMW Conical Scanners) }\end{array}$ & Bayesian CDRD & Operational \\
\hline $\mathrm{H}-02$ & PR-OBS-2 & PNPR & $\begin{array}{l}\text { Precipitation Rate at Surface with Indication of Phase } \\
\text { (LEO/PMW Cross-track Scanners) }\end{array}$ & Neural Network & Operational \\
\hline
\end{tabular}

the attributes of the new methodology and its performance when used in an applied retrieval setting. Figure 2 shows the algorithm flow diagram.

The CDRD algorithm has been designed for flexibility insofar as its application with a variety of conically scanning PMW radiometers flying on current and future satellites. Table 3 provides a summary of five such instruments, including information about their host satellite platforms, their channel frequencies and their channel polarization states. The studies of Kummerow et al. (1998), SSM/I (2000), SSMIS (2002), Kawanishi et al. (2003) and GMI (2010) provide technical information concerning the TMI, SSM/I, SSMIS, Earth Observing System (EOS) Advanced Scanning Microwave Radiometer (ASMR-E) and GMI radiometers. The information includes off-nadir viewing angles, Earth-viewing incidence angles, across-scan sweep angles, scan track lengths, beam sizes according to channel frequencies, beam-to-beam separation lengths and the down-track/along-track IFOV spatial resolutions, i.e., given according to ovate areal dimensions due to the imposed angular viewing geometries. All of these geometric factors are a function of satellite height, so that the published values are with respect to nominal satellite heights, quantities which also can be found in Table 3.

\subsubsection{Inclusion of optimal meteorological parameters as solution constraints}

The modifications and improvements of the CDRD methodology over the CRD-type methodology arise by combining meteorological parameter constraints derived from synthetic dynamical-thermodynamical-hydrological (DTH) meteorological profile variables, together with concomitant multihydrometeor microphysical profiles and multispectral PMW brightness temperature (TB) vectors into a specialized a priori knowledge database underpinning and guiding the algorithm's Bayesian retrieval solver. The meteorologicalmicrophysical knowledge variables are produced by a high resolution, nonhydrostatic model run in cloud resolving model (CRM) mode while the associated knowledge TBs are produced by an elaborate TB manifold-calibrated PMW Radiative Transfer Equation (RTE) Model System (RMS) that relates CRM environments to expected top-of-atmosphere satellite-view TBs. By applying the RMS to numerous meteorological-microphysical situations simulated by the CRM for 60 numerical storms that occurred within the European/Mediterranean Basin region, and then marshalling into a specialized database some 2.5 million modeled DTH and microphysical profiles (from which optimal meteorological constraint parameters are then derived) with linked modeled TBs - it has become possible to use the database for Bayesian interpretation of analogous measured TBs and meteorological constraint parameters.

The CRM itself is the regional/mesoscale Nonhydrostatic Modeling System (NMS) originally developed by Tripoli (1992) and recently upgraded by Tripoli and Smith (2013a, b). The heart of the model, insofar as its application with the CDRD algorithm, is its 2-water/4-ice microphysical parameterization scheme. The model simulates vertical hydrometeor profiles for all six microphysical species, which in turn represent the atmospheric cloud-precipitation media that largely determine the values of TB vectors simulated by the RMS within storm environments. The six categories consist of cloud droplets, rain drops, pristine crystals, snow pellets/flakes, ice aggregates and graupel/hail particles. The hydrometeor profiles are represented as liquid/ice water content (LWC/IWC) elements at each model level, i.e., mixing density vectors. See Casella et al. (2013) for an expanded discussion of the CDRD algorithm's NMS and RMS modeling system framework and Smith et al. (2013) for the analysis used to identify, on an a priori basis, an optimal set of six meteorological variables from which a subset of four are used as the current CDRD algorithm's constraint parameters.

The main objective in transforming from the CRD to CDRD design has been to reduce nonuniqueness effects that have plagued CRD-type schemes. Such schemes restrict interpretation of observed TBs by ignoring observable DTH information that helps constrain the influence microphysical profile subsets (i.e., the associated hydrometeors, their phases, habits, size distributions and related vertical distributions) that determine the Bayesian retrievals. In the underlying analysis required for developing the CDRD algorithm, we have found that optimal meteorological variables serve, in a generally quasi-orthogonal fashion with respect to the initial TB-based Bayesian microphysical profile solution 


\section{Cloud Dynamics \& Radiation Database (CDRD) Algorithm}
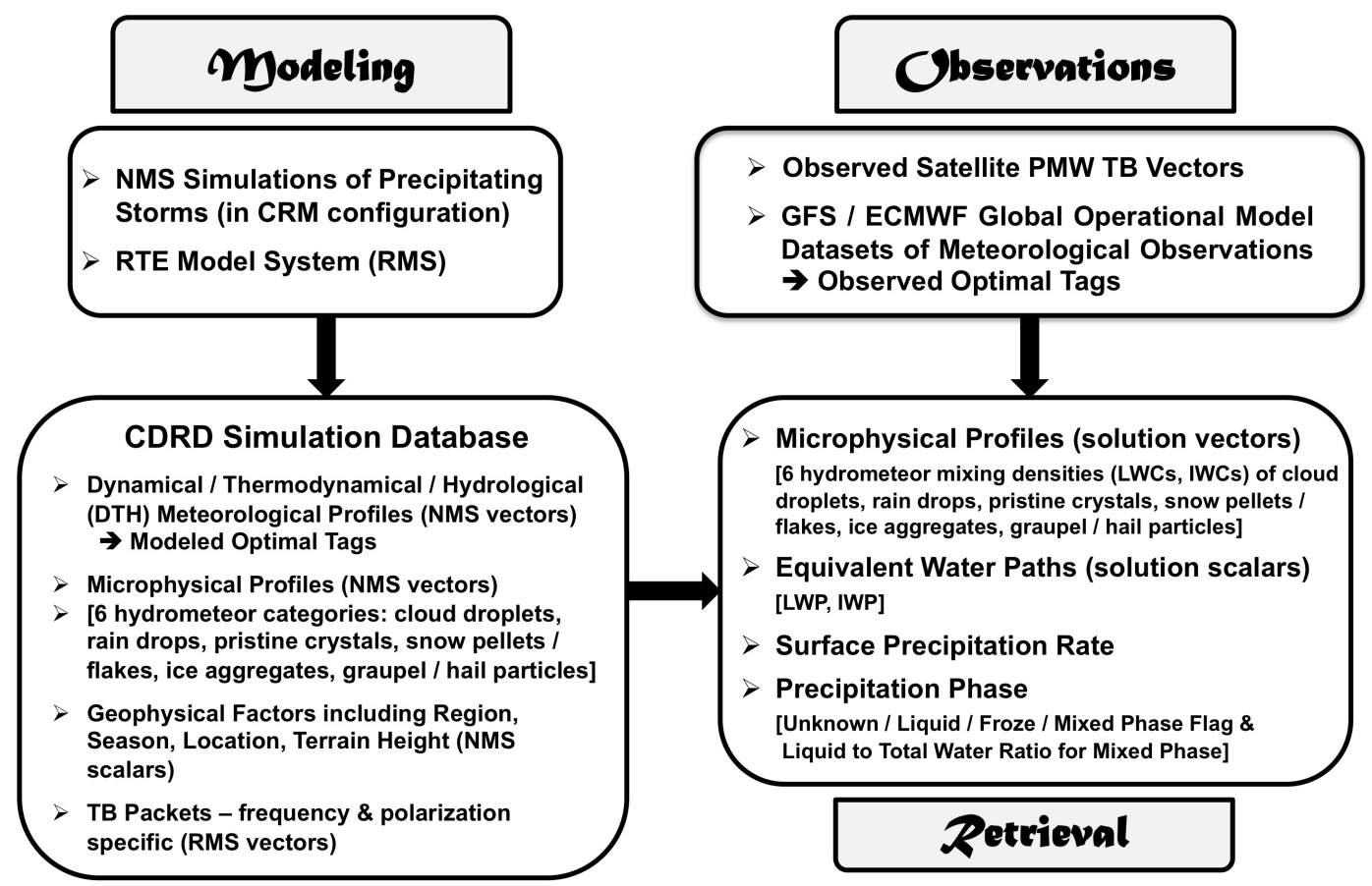

Fig. 2. Flow diagram for CDRD algorithm.

subsets, to quarantine candidate profiles which are incongruent with ambient environmental conditions for given observational situations; see Casella et al. (2013). This then serves to mitigate against the ambiguities that would otherwise arise in the solutions. The advantages of the Bayesian solution method for precipitation retrieval are well known (e.g., Evans et al., 1995; Marzano et al., 1999).

\subsubsection{RMS calibration through simulation-observation database manifold matching}

Besides corroborating the success of meteorological guidance in conditioning Bayesian retrieval solutions, Casella et al. (2013) have demonstrated the high reliability of the coupled CRM-RMS modeling system's simulated TB manifold, quantified by the close agreement to its observed counterpart. See Panegrossi et al. (1998), Casella (2010) and Casella et al. (2013) for explanations of simulationobservation database TB manifolds. This agreement is tantamount to the consistency required in data assimilation between modeled and observed influence variables. A further result is a proof-of-concept that the underlying theory behind use of meteorological guidance in a precipitation retrieval framework for removal of solution ambiguity is valid. This is obtained by combining subdivisions of the invoked optimal meteorological parameter ranges of values and showing that such partitioning associates itself with distinct microphysical profiles. It is then shown in an analogous manifold framework how ambiguity is variably distributed over a TB manifold without first isolating congruent microphysical profiles vis-à-vis any given observed TB vector.

This analysis defends the essential ambiguity criticism of a CRD-type algorithm used without meteorological extensions, and the means to overcome nonuniqueness given such constraints. Notably, the main contributor to the success of the RMS, and its role in being able to attain the CDRD algorithm's accurate results, is achieving more realistic renditions of the optical properties of the multiple hydrometeor types inherent to precipitation, particularly for frozen hydrometeors, and the adjustment of Mie theory to account for, in an unembellished fashion, the properties of nonsphericity associated with specific ice habits.

\subsubsection{Precipitation screening}

An integral part of the CDRD algorithm is a precipitation screening scheme used to determine if precipitation exists in a given IFOV before the Bayesian solver is invoked. This is done to avoid an outcome of the solver producing nonzero positive values of surface precipitation rate - even if precipitation does not actually exist in the IFOV. This would otherwise be a necessary outcome since the algorithm's database is designed such that its microphysical profile entries, selected from the 60 NMS simulations, must be associated with nonzero surface precipitation rates. Precipitation screening is often used in PMW algorithms to prevent false positive 
Table 3. Summary of five current and future conical scanning PMW radiometers with information indicating their host satellites, nominal satellite heights, channel frequencies and channel polarization states. $(\mathrm{H}, \mathrm{V}$ and RC polarization indicate horizontal, vertical and right-hand circular.)

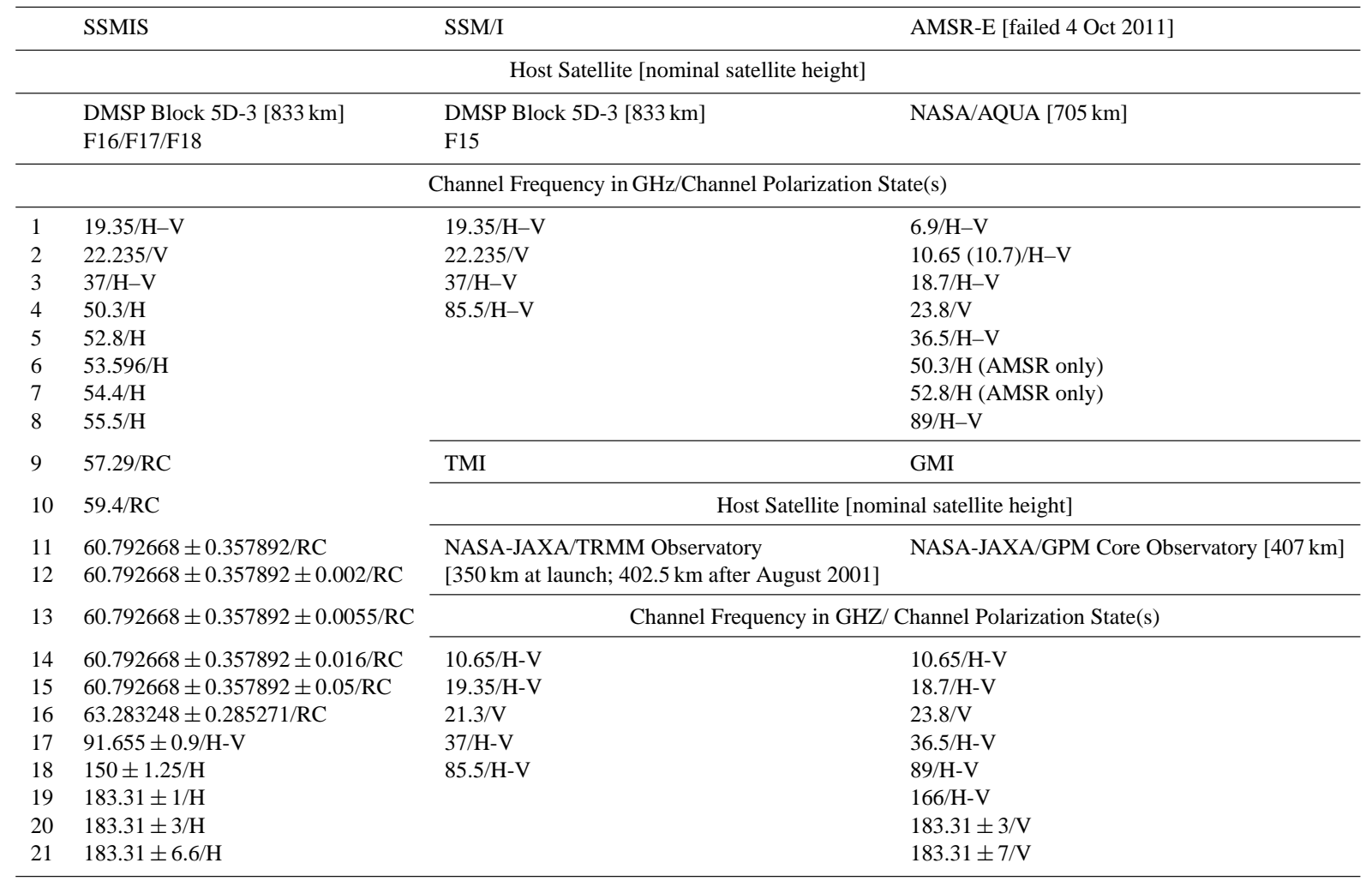

results. Since the CDRD algorithm could produce false positives but not false negatives without some guarantee of precipitation being present, to prevent a one-sided bias in false results, a screening scheme is applied. We are intermittently refining this scheme to yield minimization in the generation of false positives and negatives, and a reasonable balance between the two, as we gain more understanding from GV case studies.

The overall procedure for the current screening scheme is separated into two parts according to available channels for a given radiometer. The first part is for the conically scanning radiometers which have a set of relatively low channel frequencies between $\sim 18-95 \mathrm{GHz}$, for which four instruments can be identified in Table 3. The second part is for the radiometers which have a set of relatively high channel frequencies between $\sim 150-183 \mathrm{GHz}$, in which at least two of the frequencies around $183 \mathrm{GHz}$ are separated by at least $2000 \mathrm{MHz}$. This applies only to the SSMIS radiometer in Table 3. The explicit screening procedures for both low-end frequencies and high-end frequencies are described in Appendix A.

\subsubsection{Algorithm verification and performance evaluation against TRMM 2a12-v7 algorithm}

The retrieval algorithm's final output products consist of Bayesian interpretations of the six hydrometeor vertical profiles, as well as integrated liquid/ice water path (LWP/IWP) scalars, the surface precipitation rate and a precipitation phase flag discriminating four classes of precipitation, viz., liquid, frozen, mixed and unknown. In addition, we are experimenting with a method to provide a liquid to total water ratio for the mixed phase case, based on values of the elements at the lower levels of the LWC/IWC profile vectors.

The new CDRD algorithm has been tested and verified against its CRD predecessor on various precipitation case studies over Italy's Lazio region that were observed with both SSM/I and SSMIS radiometers, using near-coincident precision polarimetric radar measurements as the verification standard, i.e., from the Polar 55C Doppler C-band radar system operated at CNR/ISAC-Rome (Sanò et al., 2013). (In the CDRD framework, measured optimal meteorological constraint parameters are obtained from NOAA's National Centers for Environmental Prediction (NCEP) Global Forecast System (NCEP-GFS) operational meteorological data sets.) These retrievals prove highly accurate with respect to their ground radar rainfall counterparts; for convective 


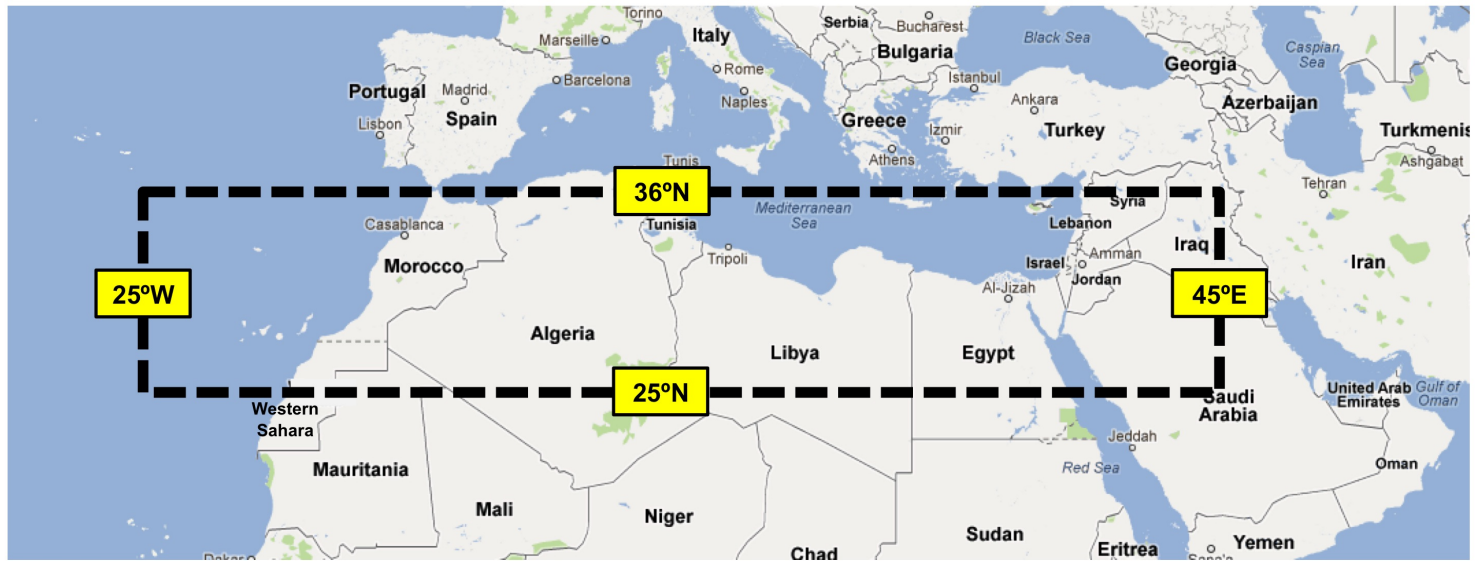

Fig. 3. Map coverage of TRMM intercomparison area over Southern Mediterranean region $\left[25^{\circ}-36^{\circ} \mathrm{N} / 25^{\circ} \mathrm{W}-45^{\circ} \mathrm{E}\right]$.

and stratiform precipitation cases, Sanò et al. (2013) find shift biases of no more than $\sim 1 \%$, slope biases between $6.5 \%$ and $1.5 \%$ and correlations between $0.84-0.88$. The radar results are obtained from a differential phase propagation (DPP) self-consistency algorithm, which intrinsically eliminates residual radar calibration errors by removing mismatched measured-derived specific differential phase shift on propagation (KDP); see Gorgucci et al. (2001) and Gorgucci and Baldini (2009).

Retrievals from the CDRD algorithm have also been compared against corresponding retrievals from the TRMM TMI facility algorithm 2a12-v7 (also called GPROF). Retrievals from both algorithms have been obtained throughout an annual cycle (2010) for the Southern Mediterranean region $\left[25^{\circ}-36^{\circ} \mathrm{N} / 25^{\circ} \mathrm{W}-45^{\circ} \mathrm{E}\right]$ as shown in Fig. 3. A summary of the intercomparison results is shown in Fig. 4. The results indicate that in a root mean square error (rmse) monthly framework, with respect to TRMM PR facility algorithm 2a25-v7: (1) the CDRD and GPROF algorithms are nearly equivalent insofar as oceanic rainfall, whereas (2) for continental rainfall (nonsnowing surface conditions), the CDRD algorithm produces significant improvements of between 10 to $55 \%$ depending on mean rainfall accumulations for the given months of the year, with an overall annual improvement of $16 \%$. Moreover, on an annual basis, the CDRD algorithm relative to the GPROF algorithm exhibits moderate improvements in correlation coefficient $(r)$ with respect to PR retrievals for both oceanic and continental rainfall (0.65 vs. 0.60 and 0.59 vs. 0.54 , respectively). Finally, insofar as mean error $(\bar{\mu})$ with respect to the PR, the CDRD algorithm for continental rainfall over the annual cycle exhibits only a small difference of $0.17 \mathrm{~mm} \mathrm{~h}^{-1}$ relative to $0.78 \mathrm{~mm} \mathrm{~h}^{-1}$ for GPROF - a factor of 4.6 improvement. Thus it is apparent that the CDRD algorithm is competitive with GPROF for ocean applications, and provides a significant improvement for continental applications. More exhaustive tests are underway to corroborate this result.

\subsubsection{Near future improvements}

As with any algorithm, the standing rule is that there are always avenues for improvement, and the CDRD algorithm stands as no exception to this rule. We envision continued experiments with more exact implementation of the five optimal tags that we are using in the algorithm's constraint formulation (four meteorological constraints and terrain height as a geophysical constraint), also noting that the Smith et al. (2013) study identifies two additional optimal meteorological constraint tags that we have not yet studied. As also alluded to in Sect. 3.2.4 concerning the PNPR algorithm, for certain surfaces (mostly coastal, arid and snow/ice landscapes), the a priori precipitation screening component of both ISAC-Rome algorithms can represent a tricky problem. Therefore, we will continue to examine refinements to the CDRD and PNPR algorithms' screening schemes. In a related issue, tied in with the CDRD algorithm's solution solver, is the matter of assigning phase to the surface precipitation, i.e., unknown, rainfall, snowfall or mixed, and if mixed - at what liquid to total water ratio. In its present version the phase flag determination is based on the findings of Grody et al. (2000), Rosenkranz (2003), and Surussavadee and Staelin (2009). In these studies snowfall is detected by use of the 20.3, 50.3 and $89 \mathrm{GHz}$ TBs, including combinations of these channels. Phase identification involves comparing the selected TBs and their combination quantities with various thresholds to distinguish between liquid or frozen precipitation, including detection of falling snow over snow or ice backgrounds. We anticipate more research is needed for this element of the CDRD algorithm, mostly in how to best determine the ratio for the mixed phase case from the lower elements of the hydrometeor LWC/IWC mixing density vectors.

We intend to examine how we might include lightning sensor observations, since we currently have modeling capability to simulate lightning activity in convectively active 


\section{Intercomparison of CDRD and GPROF-v7 TRMM TMI Retrievals over \\ Southern Mediterranean Region for Annual Cycle [25-36 $\left.\mathrm{N} / 25^{\circ} \mathrm{W}-45^{\circ} \mathrm{E}\right]$}
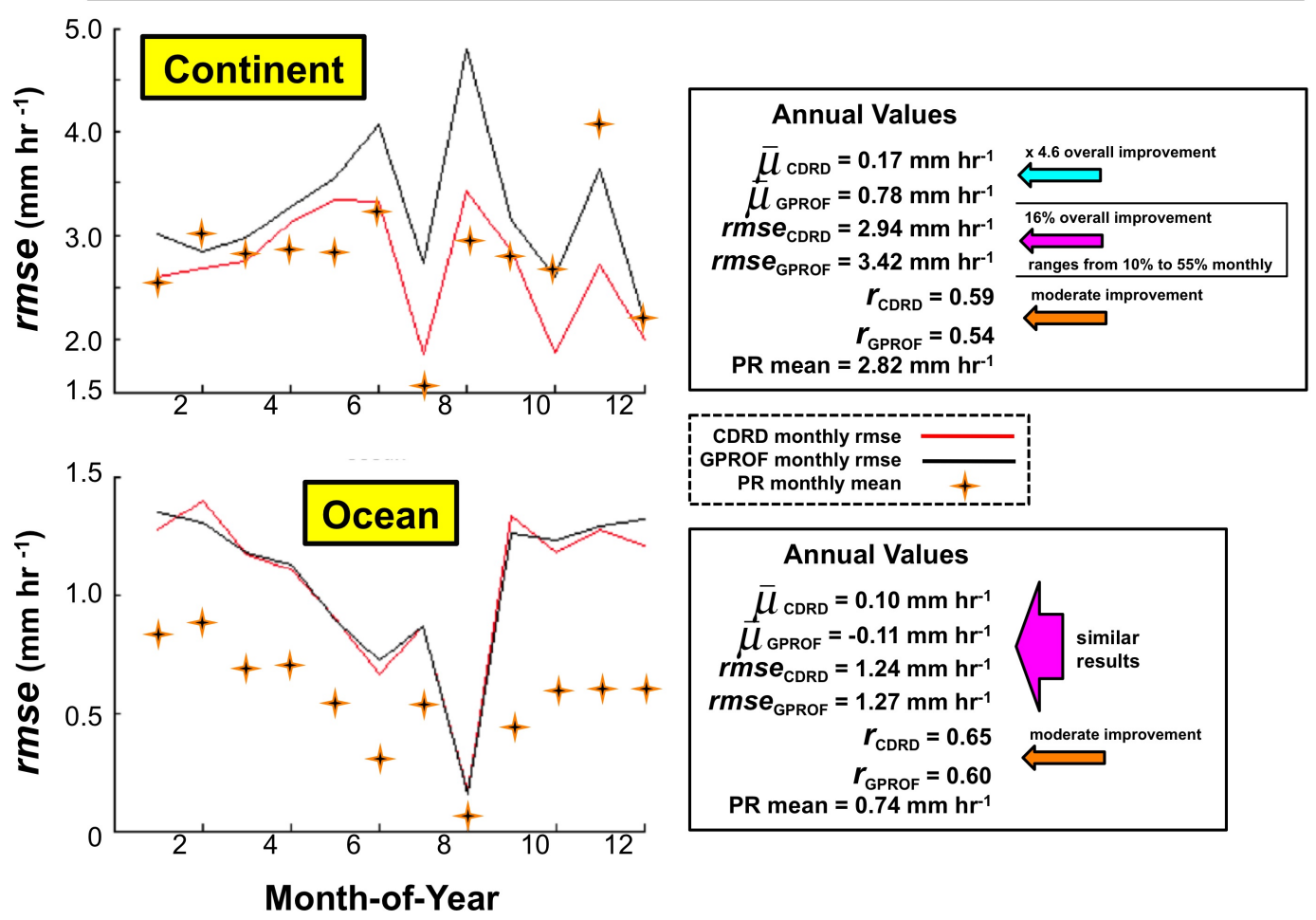

Fig. 4. Results of algorithm intercomparisons based on annual cycle (2010) of all TRMM level 2 data over the Southern Mediterranean region in which CDRD and GPROF-v7 (2a12) TMI-based rain retrievals are independently compared to PR-v7 (2a25) radar retrievals. (Statistics for mean error $(\bar{\mu})$, root mean square error (rmse) and correlation coefficient $(r)$ are given for both CDRD and GPROF algorithms, as well as PR mean value - for both land and ocean.)

environments (Formenton et al., 2013). Lightning data are now readily available and deserve attention in precipitation retrieval algorithms. Also, we are exploring the possibility of extending the area of application of the algorithm to cover the reference MSG satellite full-disk region. Whereas generating further representative NMS simulations for the oceanic areas of this region does not represent any concern, producing an effective set of NMS simulations for the African continent does have some issues, but only in the sense that an effective spatiotemporal distribution of representative storms will be needed. We are currently examining a strategy to determine this. In addition, we will need to extend the viability of the database to the higher northern latitudes where light rain, light snow and light mixed phase precipitation is prevalent. Although generating the necessary simulations for extending the database is straightforward, screening for light liquid or frozen precipitation is a seriously difficult problem and not one for which we would expect a great deal of progress in using current PMW instrument technology. Not until the next generation of PMW radiometers are in space during the GPM era, can we expect significant progress to be made on this problem. However, this issue does draw attention to our intent to continue with case studies for which high quality H-SAF GV network data are available. Finally, in expanding coverage we will be generating a number of new NMS simulations for the tropics and subtropics. Therefore we intend to use retrievals from the three main TRMM algorithms for GV studies. In this vein, we anticipate that once the extended database is completed, we will examine how to better develop it as a common database in conjunction with the PNPR algorithm.

\subsection{PMW Neural-net Precipitation Retrieval (PNPR) algorithm}

The H-SAF PR-OBS-2 neural network algorithm, referred to at ISAC-Rome as the PNPR algorithm, has been motivated by the investigations of Surussavadee and Staelin (2008a, b). They developed an Artificial Neural Network (ANN) based precipitation retrieval algorithm for applications with measurements from AMSU-A/MHS (or/AMSU-B, i.e., MHS's ancestor instrument on an earlier generation of NOAA POES satellites). They trained their algorithm through a database generated from CRM precipitation simulations. They used as 
their CRM basis, the Pennsylvania State University/National Center for Atmospheric Research (PSU/NCAR) Mesoscale Model-5 (MM5), described by Dudhia (1993) and Grell et al. (1994), with which they produced multiple simulations at a number of locations on the globe.

The PNPR algorithm is based on a new optimal three-layer ANN, which has derived its training database from the same 60 NMS simulations and the same RMS that are used for the CDRD algorithm, as described in Casella et al. (2013). The motivation for using a neural network algorithm solution solver stems from the PNPR's applications with cross-track scanning radiometer measurements. These are less manageable for a Bayesian solver because the changing view angle across a scan passage, and the concomitantly changing atmospheric path, introduce view angle-dependent errors in the RMS calculations. This is unlike the case for conical scanners where RMS-generated errors are consistent across the scan passage and thus detectable as systematic errors when conducting validation checks. When view-angle dependent errors enter retrievals, they complicate how systematic error should be expressed and impose a reduced confidence in formulating Bayesian probabilities. It is this confidence issue that motivates a turn to a neural network approach when using cross-track scanner data. We find that an ANN is able to overcome some of the view angle-dependent uncertainties - at the expense of moving away from a pure physicsbased solution. We point out that the view angle-dependent error problem, insofar as using a pure RTE physics-based approach with PMW cross-track scanner measurements, was first explained by Kidder (1976), based on use of data from the first PMW precipitation radiometer, the cross-track scanning 19.35 GHz Electrical Scanning Microwave Radiometer (ESMR); see Wilheit (1972).

\subsubsection{Training database}

H-SAF seeks to support precipitation algorithms for crosstrack scanning radiometers as consistent as possible with those for conically scanning radiometers, as well as precipitation algorithms optimized for the European/Mediterranean Basin region. This explains why we have developed the training database for the PNPR algorithm based on the same physical foundation used for the CDRD algorithm - including the same NMS simulations and RMS methodology. While the CDRD algorithm uses its database repeatedly to obtain a priori potential solution profiles for its Bayesian solver for retrieval situations at the times they occur, the PNPR algorithm uses its database only once during the training process, to develop the functional relationships needed between the inputs (i.e., TBs, geographical/seasonal factors, pixel view angle) and the outputs (i.e., surface precipitation rate, phase flag).

In order to calculate surface emissivities needed by the RMS's embedded Surface Emissivity Module (SEM) (see Smith et al., 2013), for each AMSU and MHS channel frequency, according to the polarization state and varying lo- cal zenith angle $(\theta)$, emissivities are first calculated for the horizontally/vertically orthogonal polarization (H-pol/V-pol) states $\left(\varepsilon_{\mathrm{p}}, \varepsilon_{q}\right)$, then combined to calculate an effective emissivity ( $\varepsilon_{\text {eff }}$ ) using the relationship discussed in Prigent et al. (2005), i.e., $\varepsilon_{\text {eff }}(\theta)=\varepsilon_{\mathrm{p}}(\theta) \cos ^{2}(\theta)+\varepsilon_{q}(\theta) \sin ^{2}(\theta)$. In this expression, $p$ represents either H-pol or V-pol depending on a given channel's polarization state at nadir, while $q$ represents the opposing state.

The fifteen channel frequencies of the AMSU-A instrument are 23.8, 31.4, 50.3, 52.8, 53.6, 54.4, 54.94, $55.5,57.29,5$ at $57.29 \pm \Delta F \pm \Delta f$ and $89 \mathrm{GHz}$ (where $\pm \Delta F \pm \Delta f$ represents either double or quadruple symmetric sideband frequency positions along the $57.29 \mathrm{GHz}$ $\mathrm{O}_{2}$ line's wing - necessary for temperature sounding), while the five frequencies of the MHS radiometer are 89, 157, $183.31 \pm 1, \quad 183.31 \pm 3$ and $183.31 \pm 7 \mathrm{GHz}$. This information is summarized in Table 4 and accessible in more detail from AMSU-A (2009) and MHS (2009). The IFOV resolutions/shapes are a function of the radiometer, the view angle and the height of the satellite, where shape is expressed in terms of cross-track (CT) and downtrack (DT) elliptic dimensions. Both the AMSU-A and MHS radiometers use their own common beam sizes, specific to each radiometer, unvarying with respect to channel frequency, i.e., the IFOV resolutions are independent of the frequency dependent diffraction limits. For example, for the AMSU-A radiometer at a nominal satellite height of $833 \mathrm{~km}$, the nadir and scan edge IFOV resolutions/shapes, respectively, are $49.33-\mathrm{CT} \times 48.17-\mathrm{DT} \mathrm{km}{ }^{2} /$ near-circular and $179.89-\mathrm{CT} \times 80.8-\mathrm{DT} \mathrm{km}{ }^{2} /$ extreme-ovate, while for the MHS radiometer at the same satellite height, the nadir and scan edge IFOV resolutions/shapes, respectively, are 20.36-CT $\times 16.59-\mathrm{DT} \mathrm{km} \mathrm{km}^{2} /$ mild-ovate and 67.14-CT $\times 27.91$-DT km²/extreme-ovate. Refer to Bennartz (2000) for the analytical expressions that we employ for the IFOV resolutions.

Caution is taken to mitigate against nonhomogeneous IFOV beam filling affecting the retrievals (i.e., variability in precipitation cover within a given IFOV produces errors in retrievals because of the underlying nonlinear relationship between TBs and precipitation rates), an effect referred to as nonuniform beam filling (NUBF) error. This is critical for larger IFOV footprints. To reduce NUBF errors, the initial simulated TBs for the database, initially taken at the CRM's 2-km resolution, are spatially averaged (convolved) using the AMSU-A/MHS Gaussian antenna pattern functions out to $\pm 1 \sigma$ widths, these functions varying with view angle. In replicating the characteristics of the AMSU-A and MHS radiometers, the RMS makes calculations at 45 beam centers $(\theta s)$ using steps of $1.1^{\circ}$, equivalent to the number of mechanical scan stops used on the MHS instrument, scanning to either side of nadir over a tilt angle from nadir beam center to edge beam center of $48.33^{\circ}$ for a $1 / 2$ scan angular view field of $49.5^{\circ}$. Therefore, each possible NMS cloud structure must be associated to 45 different TB vectors (for each of the 
Table 4. Same as Table 3 except for three cross-track scanning PMW radiometers. ( $R$ polarization indicates rotation-with-scan).

\begin{tabular}{|c|c|c|c|}
\hline & AMSU-A & AMSU-B & MHS \\
\hline \multicolumn{4}{|c|}{ Host Satellite [nominal satellite height] } \\
\hline 1 & NOAA-18/19 POES [833 km] & Pre-NOAA-18 POES Platforms [833 km] & NOAA-18/19 POES [833 km] \\
\hline 2 & METOP-A/B [817 km] & & METOP-A/B [817 km] \\
\hline \multicolumn{4}{|c|}{ Channel Frequency in GHz/Polarization:Polarization State at Nadir } \\
\hline 1 & $23.8 / R: \mathrm{V}$ & $89 \pm 0.9 / R: \mathrm{V}$ & $89 / R: \mathrm{V}$ \\
\hline 2 & $31.4 / R: \mathrm{V}$ & $150 \pm 0.9 / R: \mathrm{V}$ & $157 / R: \mathrm{V}$ \\
\hline 3 & $50.3 / R: \mathrm{V}$ & $183.31 \pm 1 / R: \mathrm{H}$ & $183.311 \pm 1 / R: \mathrm{H}$ \\
\hline 4 & $52.8 / R: \mathrm{V}$ & $183.31 \pm 3 / R: \mathrm{H}$ & $183.311 \pm 3 / R: \mathrm{H}$ \\
\hline 5 & $53.596 \pm 0.115 / R: \mathrm{H}$ & $183.31 \pm 7 / R: \mathrm{V}$ & $183.311 \pm 7 / R: \mathrm{V}$ \\
\hline 6 & $54.4 / R: \mathrm{H}$ & & \\
\hline 7 & $54.94 / R: \mathrm{V}$ & & \\
\hline 8 & $55.5 / R: \mathrm{H}$ & & \\
\hline 9 & $57.29 / R: H$ & & \\
\hline 10 & $57.29 \pm 0.217 / R: \mathrm{H}$ & & \\
\hline 11 & $57.29 \pm 0.3222 \pm 0.048 / R: \mathrm{H}$ & & \\
\hline 12 & $57.29 \pm 0.3222 \pm 0.022 / R: \mathrm{H}$ & & \\
\hline 13 & $57.29 \pm 0.3222 \pm 0.01 / R: \mathrm{H}$ & & \\
\hline 14 & $57.29 \pm 0.3222 \pm 0.0045 / R: \mathrm{H}$ & & \\
\hline 15 & $89 / R: \mathrm{V}$ & & \\
\hline
\end{tabular}

45 view angles), noting a complete MHS instrument scan involves 91 steps, but with angular symmetry around the center step. (Note the AMSU-A instrument uses a $3.3^{\circ}$ angular step at 15 beam centers from nadir to either scan edge, again for $\mathrm{a}^{1} / 2$ scan angular view field of $49.5^{\circ}$.)

In the PNPR database, the correspondence between TB vectors, along with their associated hydrometeor structures and surface precipitation rates, is complicated by the dependence of spatial resolution along a radiometer scan due to the varying view angle. In order to produce unique relationships between the TB vectors for the individual viewing angles and the associated surface precipitation rates, a variable sensor resolution (VSR) is defined according to the nominal MHS resolution, varying from $16 \times 16 \mathrm{~km}^{2} /$ circular at nadir to $26 \times 52 \mathrm{~km}^{2} /$ ovate at scan edge. ${ }^{3}$ Thus, the surface precipitation rates must be averaged for 45 VSRs with precipitation products delivered to the H-SAF product data center tagged accordingly. This means that the PNPR database has 45 times greater density in precipitation structure entries than the CDRD database, which itself contains some 2.5 million entries for the European/Mediterranean Basin region.

\subsubsection{Precipitation screening}

As noted in Sect. 3.1.3, both the PNPR and CDRD algorithms use screening schemes to detect precipitating condi-

3 For the CDRD algorithm, an invariant mean sensor resolution (MSR) is defined according to the resolution of the SSMIS $91.655 \mathrm{GHz}$ channels $\left(13.2 \times 15.5 \mathrm{~km}^{2}\right)$; this resolution is used for all CDRD precipitation products. tions within a given radiometer IFOV. These schemes precede the application of the retrieval solution solvers for either algorithm in order to ensure that the solvers are acting only on precipitating pixels. Since the PNPR algorithm is used with the AMSU-A/MHS and /AMSU-B radiometers, it uses the high-end frequencies screening procedure following Chen and Staelin (2003) as described in detail in Appendix A.

\subsubsection{Determination of optimal artificial neural network (ANN)}

Like the human brain, ANNs are repeatedly exposed to inputs, responding by varying the strength of the connections between its neurons based on the inputs (see Haykin, 1998, 2009). Thus, learning for ANNs is accomplished by use of an iterative process, similar to say, relaxation-based inversion but unlike single step-based schemes such as use of regression equations or accumulations according to Bayesian probabilities. By the same token, a simplifying feature of the PNPR algorithm is that it uses a unique ANN that retrieves the surface precipitation rate for all types of surface backgrounds represented in its database, i.e., land, ocean, ice, snow or coast. This prevents different precipitation estimates being inconsistent when an observed precipitation system extends over two or more types of surfaces. Note the PNPR outputs consist of both the surface precipitation rate and a phase flag indicating liquid, frozen, mixed or unknown conditions. The PNPR algorithm cannot provide the liquid-total ratio for the mixed phase case because, unlike the CDRD algorithm, 


\section{PMW Neural-net Precipitation Retrieval (PNPR) Algorithm}

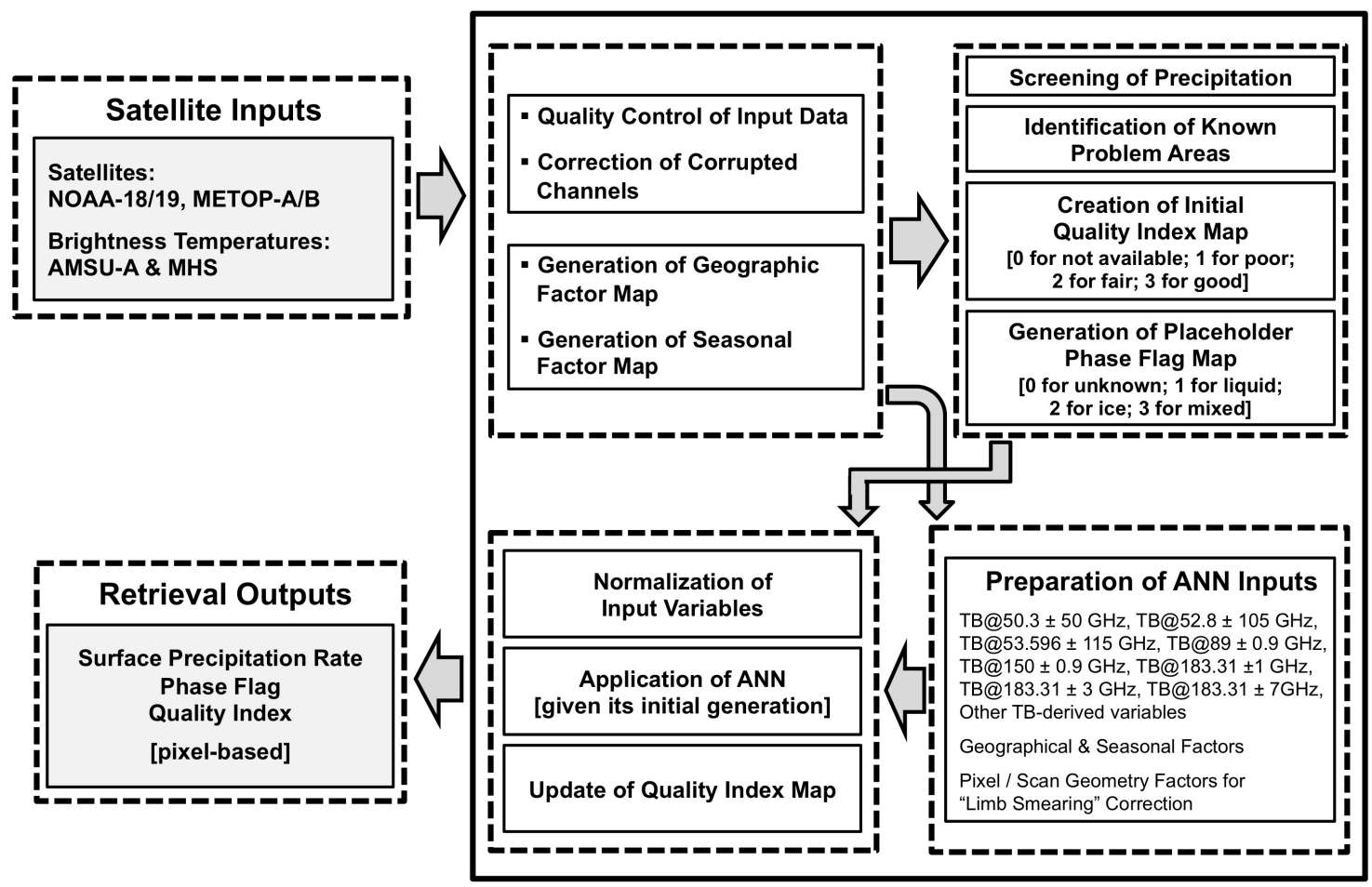

Fig. 5. Flow diagram for the PNPR algorithm.

it does not retrieve vertical hydrometeor profiles for the six microphysical species.

As input data, the PNPR algorithm incorporates TBs measured by the AMSU-A and MHS radiometers. It considers three AMSU-A channels $(50.3 \pm 50,52.8 \pm 105,53.596 \pm$ $115 \mathrm{GHz})$, all five MHS channels $(89 \pm 0.9,150 \pm 0.9$, $183.31 \pm 1,183.31 \pm 3,183.31 \pm 7 \mathrm{GHz})$ and various additional channel-derived variables. In order to reduce ambiguity, other geophysical inputs (i.e., latitude, terrain height, surface type, season) guide the algorithm towards selecting database members that are most representative of an observed scene. The pixel number along the scan is an additional principal input parameter used to determine the degree to which limb smearing is to be reduced, the effect produced by changing atmospheric path length along the scan (Goldberg et al., 2001). The ANN itself performs the limb correction.

In the process of finding the ANN most suitable for obtaining actual retrievals of surface precipitation rates, the training database is divided into two pieces, the first being used for the actual training (ground truth piece) and the second for providing the synthetic TBs used in a subsequent verification analysis (GV piece). Different ANN configurations have been tested, varying the number of layers and perceptrons (i.e., weighted linear predictor functions) at each layer. The iterative method considers both reduction of the rmse and enlargement of the $r$ between the synthetic surface precipitation rates in the ground truth piece of the database and the ANN retrievals associated with the corresponding synthetic TBs, and the avoidance of overfitting, i.e., the tendency for a given ANN to tilt toward perfection in the retrievals from the ground truth piece of the database, yet unable to adapt to differing situations. Notably, both pieces must be representative of all precipitation events contained within the collective database. The choices for size and specific members of each piece are thus crucial in obtaining an effective evaluation of the final ANN's performance, and thus for each piece, database members in 45-entry sets from 60 original simulations are selected randomly. A maximum threshold for rmse and minimum threshold for $r$ are used for optimal performance.

The result of the training process is an optimal three-layer ANN. In the 1st layer, the number of perceptrons equals the number of TB + TB-derived inputs. For the 2 nd and 3 rd layers, twenty and eight perceptrons are selected, respectively. The use of the additional layers is necessary to prevent: (1) overfitting, measured by small values of rmse during the learning procedure followed by large values during the verification analysis, and (2) too little variability in precipitation rates along with an inability to identify consistently heavy precipitation. Once the optimal ANN is created, a final check of the retrievals is conducted to determine their 
stability to varying input, accomplished by perturbing the input TBs with random noise within allowed errors, followed by retrieval calculations. The perturbation retrievals are then compared to those obtained from the original TBs to obtain corresponding differences. Since these comparisons do not reveal significant differences, the stability of the optimal ANN is confirmed, enabling its effective implementation within the PNPR algorithm.

Figure 5 shows a flow diagram of the PNPR algorithm. First, the input TBs undergo a quality check to replace occasionally corrupted TBs with synthetic values created by the ANN using neighboring TBs at the same and different channel frequencies. Additionally, two maps of geographical and seasonal information are created for the observed scene. Then, four different procedures are carried out: (1) screening tests for detection of surface precipitation areas, (2) identification of areas where the algorithm is known to be less accurate, (3) creation of a map of initial quality indices based on procedure 2 and to be associated with the final surface precipitation retrievals, and (4) creation of an initial placeholder map of the phase flag of the final precipitation retrievals. Now the optimal ANN itself is applied, generating the final retrieved values of surface precipitation rate and associated phase flag. A separate element of the ANN controls the TB inputs for assigning the phase flag, based on findings in Grody et al. (2000), Rosenkranz (2003) and Surussavadee and Staelin (2009). To complete the retrieval process, the quality index is updated, accounting for the magnitudes of the retrieved surface precipitation rates. Thus, besides the surface precipitation rate and its phase flag, the quality index for each pixel is also output, assigned as poor, fair, good or unknown.

Since both CDRD and PNPR algorithms have been developed using the same physical basis, mainly differing in their choice of solution solvers (averaging over a priori Bayesian probabilities for CDRD versus neural network training based relationships for PNPR), it is reasonable to expect a certain degree of consistency in their precipitation retrievals when the algorithms are applied to close-in-time measurements acquired by conical and cross-track scanning radiometers for the same rainfall event. Figure 6 shows a comparison of retrieved surface rain rates for the two algorithms, based on DMSP/SSMIS and METOP-A/AMSU-A/MHS overpasses during the 20 October 2011 flash flood event in Rome, Italy, noting the METOP-A overpass only lags the DMSP overpass by $11 \mathrm{~min}$. The intercomparison reveals close correspondence in rain rates for the flood event, noting that the AMSU$\mathrm{A} / \mathrm{MHS}$ scan is not centered on the main precipitation event, instead viewing the scene at the outer left scan edge where spatial resolution undergoes its greatest deterioration. Overall, even given the 11-min time difference in overpasses and the deteriorated resolution in the cross-track scanner measurements, the intercomparison results effectively corroborate the capabilities of the two algorithms in reporting similar rainfall results from very different retrieval solution method- ologies using greatly different radiometer scanning technologies.

\subsubsection{Near future improvements}

Most of the issues discussed in Sect. 3.1.5 concerning the CDRD algorithm will also be addressed in terms of nearterm improvements to the PNPR algorithm. However, our foremost concerns will be refinement of the algorithm's precipitation screening scheme and the determination of a phase flag as consistent as possible with that of the CDRD algorithm (neglecting the liquid-total ratio for the mixed phase case). To make these refinements, the PNPR algorithm will undergo additional verification tests based on H-SAF GV radar data, with particular emphasis given to case studies around coastlines, arid regions, and at high latitudes experiencing light rain or snow. Notably, the latter situation is the most difficult, involving detection of stratiform precipitation over snow and/or ice surfaces which can occur in any of the three phases. As noted earlier, insofar as progress with the screening scheme, these results will have application to the CDRD algorithm in applications with SSMIS data.

\section{Future opportunities for algorithm development in GPM era}

Because water cycling and the availability of fresh water resources, including their predicted states, are of such immediate concern to most nations, and because precipitation is fundamental to all environmental water issues, developing a space-based, globally-inclusive precipitation measuring system has become a pressing issue for a large body of nations.

\subsection{Advent of GPM era}

The goal of the GPM mission is the development of a next generation, space-based measuring system which will fulfill the requirements for global, frequent and accurate precipitation measurements. The GPM mission is being developed as an international collaboration of space agencies, weather and hydrometeorological forecast services, research institutions, and individual scientists. It will serve as the flagship space mission for a number of water-related research and applications programs. These include international research programs involved with the global water and energy cycle (GWEC), particularly the World Climate Research Program (WCRP)/Global Energy and Water Cycle Experiment (GEWEX), and will support basic research, applications-oriented research, and operational environmental forecasting throughout individual nations and consortiums of nations. A principal contributor in this context is expected to be the EUMESAT Hydrology SAF.

The design and development of the GPM mission is an outgrowth of valuable knowledge and published findings enabled by TRMM. Given the TRMM experience and 


\section{Rome, Italy: Flash Flood (20 Oct 2011) [Surface Rain Rates]}

CDRD Algorithm at 8:09 UTC using

DMSP / SSMIS-F18 Conical Scanner [resolution: $15 \times 15 \mathrm{~km}^{2}$ ]

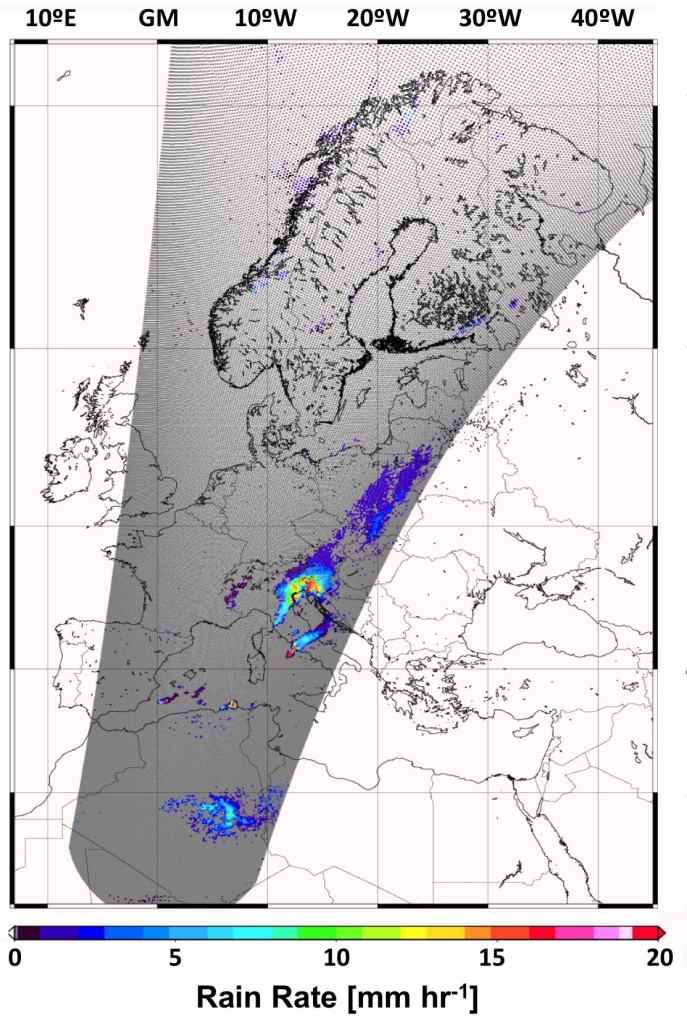

PNPR Algorithm at 8:20 UTC using METOP-A / AMSU-A \& MHS Cross-track Scanners [resolution: $16 \times 16 \mathrm{~km}^{2}$ at nadir ; $27 \times 50 \mathrm{~km}^{2}$ at scan limits]

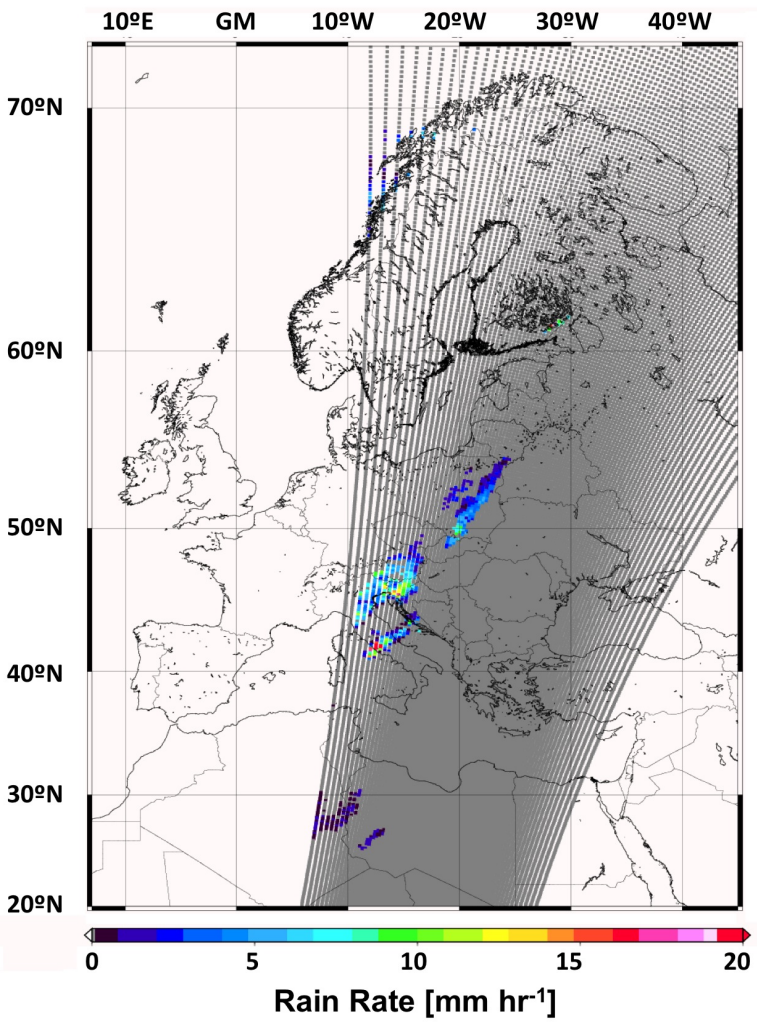

Fig. 6. Comparison of retrieved surface rain rates for the 20 October 2011 flash flood event in Rome, Italy. Left panel shows results for CDRD algorithm applied to measurements from DMSP/SSMIS-F18 conical scanner while right panel shows results for PNPR algorithm applied to measurements from METOP-A/AMSU-A \& MHS cross-track scanners. Note lag of 11 min between DMSP and METOP-A satellite overpasses and difference in spatial resolutions due to difference in instrument scanning designs.

from a consideration of the basic physical principles associated with direct sensing of precipitation from space, it is now recognized that the GPM mission requires a constellation of satellites, some dedicated, and some conveniently available through other experimental and operational missions supported by various of the world's space agencies, i.e., "satellites of opportunity"; see Smith et al. (2007) and http://pmm.nasa.gov/.

The heart of the GPM constellation will be the GPM Core Satellite, under joint development by NASA and the Japan Aerospace Exploration Agency (JAXA). As with TRMM, the basic work-share arrangement between NASA and JAXA is that NASA provides the radiometer, the satellite bus and the ground segment, while JAXA provides the radar system, the launch vehicle and the launch operations. The Core Satellite is the central rain measuring observatory equipped with a pair of radars (called the DPR for Dual-frequency Precipitation Radar) at Ku-/Ka-band frequencies (see Iguchi et al., 2002; Nakamura et al., 2005; and http://www.jaxa.jp/ $\mathrm{pr} /$ brochure/pdf/04/sat04.pdf), and a high resolution, multichannel PMW rain radiometer called the GPM Microwave Imager (GMI) ${ }^{4}$. The GPM Core Satellite is required to serve as the calibration reference system and the fundamental microphysics sensor package supporting an integrated satellite measuring system made up of six to ten constellation satellites, depending on the time frame. Each constellation satellite is required to carry one or more precipitation sensing instruments, with a minimum requirement of one PMW ra-

\footnotetext{
4 The 2nd author of this paper developed the scientific requirements for the GMI and was one of four principals of the design team that produced the instrument's engineering specifications; see Bidwell et al. (2005) and Newell et al. (2010).
} 
diometer equipped with an appropriate set of precipitation channels.

The GPM mission will have the capability to provide physically-based retrievals on a global basis, with $\sim 3$-h sampling assured at any given Earth coordinate $\sim 90 \%$ of the time. Such frequent diurnal sampling is made possible by a mixed non-sun-synchronous/sun-synchronous satellite orbit architecture. Nonetheless, regardless of the overall mission design and implementation plan, the quality of the rainfall estimates will still come down to the quality of the algorithms conducting the retrievals and producing the precipitation products. This is where the CDRD and PNPR algorithms become relevant. As noted, they will be able to improve upon the standing TRMM era capabilities for mid-latitude European applications, for three very specific reasons that will be made possible by the onset of the GPM era: (1) much greater spatial resolution of GMI radiometer measurements compared to the TRMM TMI (made possible by the much larger GMI $1.22 \mathrm{~m}$ antenna compared to the TMI $0.6 \mathrm{~m}$ antenna) over a frequency spectrum twice that of TMI, encompassing thirteen channels at 10.65, 18.7, 23.8, 36.5, 89, 165 and $183 \pm 3 / \pm 7 \mathrm{GHz}$, in which all but the 23.8 and 183 frequencies incorporate $\mathrm{H}-$ pol and $\mathrm{V}$-pol orthogonal polarization separation (the latter three frequencies only requiring Vpol channels) (see Table 3); (2) much better hydrometeor size distribution resolving capability due to the inclusion of the two-frequency Ku-band (13.6 GHz)/Ka-band ( $35 \mathrm{GHz})$ DPR in place of the single-frequency Ku-band (13.8 GHz) PR; and (3) an improved GV program. Each of these new capabilities of the GPM mission has direct bearing on the anticipated improvement of the CDRD and PNPR algorithms, for reasons given in the next three paragraphs.

Reason 1: The longest standing barrier preventing significant improvement in PMW precipitation retrieval stems from the small antennas used on the radiometers. For example, the best of these radiometers, the TRMM satellite's TMI, only uses a $0.6 \mathrm{~m}$ antenna. The antenna size along with satellite height, define the diffraction limited IFOV at any given channel frequency, unless otherwise decreased through engineering-imposed default resolutions. The problem with PMW retrieval has always been that the relatively large IFOVs, determined by the use of relatively small radiometer antennas, automatically bring about nonlinear errors in the retrievals due to NUBF. The GPM Core Satellite's antenna size is $1.22 \mathrm{~m}$, i.e., over twice that of the TMI. As pointed out in the analysis given by Smith et al. (2007) based on representative spatial scales of precipitation elements in modeled clouds, such a geometric doubling will remove much of the NUBF error problem at lower frequencies because of the relatively smaller GMI IFOVs. In fact, one more doubling at characteristic LEO satellite heights will reduce much of the NUBF error in the $18-23 \mathrm{GHz}$ frequency range, and one more doubling af- ter that would be similarly effective in reducing NUBF error at the $10.7 \mathrm{GHZ}$ frequency - effectively freeing PMW precipitation retrieval from serious NUBF error problems. (It is important to note that, for the most part, maximum PMW radiometer antenna sizes have been limited by the front bay dimensions of the rockets used to launch the relatively bulky instruments always in conjunction with other instruments, and the unwillingness to use somewhat risky antenna unfolding mechanisms that would increase allowable antenna dimensions.) Thus, the engineering design of the GMI's antenna will enable significant improvement in the CDRD and PNPR algorithms' retrieval accuracy. Moreover, the GMI frequency range from $10.7-183 \mathrm{GHz}$, a first for a spaceborne PMW radiometer, will enable improvements in retrieval accuracy across a wider spectrum of surface precipitation rates, and thus will extend the CDRD and PNPR algorithms' utility to high latitudes where light rates of surface rainfall/snowfall are prevalent; Mugnai et al. (2007).

Reason 2: Because the GPM Core Satellite will be flying a 2-frequency radar system and the satellite's inclination will be $65^{\circ}$, the anticipated use of differential frequency techniques will enable learning a great deal about hydrometeor size distribution characteristics up to high latitudes, that is will be able to diagnose at least two moments of the size distributions up to the highest latitudes deemed important by the H-SAF program. This knowledge will be helpful in improving the RMS used by the CDRD and PNPR algorithms, particularly the RMS components pertaining to hydrometeor optical properties and the associated single scatter properties of the six liquid/frozen hydrometer categories underlying the algorithms' physics. For this reason alone, the GPM era should bring about significant strides in precipitation retrieval, some which can be anticipated, others which will reveal themselves as the GPM era unfolds. By the same token, since the swath widths of the two GPM Core Satellite's radars (120 and $245 \mathrm{~km}$ cross-track for Ka-band and Ku-band, respectively) are significantly smaller than the swath width of the GMI (904 km conical-track), it will be necessary to use either physically-based similarity techniques or statisticallybased correlative techniques to acquire radar-quality retrievals in the radiometer swath areas outside the views of the two radars. Thus, this issue represents a future topic of research.

Reason 3: Effective GV analysis of a precipitation retrieval algorithm is an almost sacrosanct requirement before such an algorithm can be taken seriously. In the development of the CDRD and PNPR algorithms we have made significant progress in GV analyses; e.g., see Casella et al. (2012), Sanò et al. (2013), Puca et al. (2013) and the results presented in prior Sects. 3.1.4 
and 3.2.3. In the GPM era there will be a significant expansion of GV networks, GV capabilities and GV accuracies in the acquired data. All of such expansion will contribute to the improvement of the CDRD and PNPR algorithms, through case study analyses, intercomparisons with GPM facility precipitation retrieval algorithms and improved understanding of the physics of precipitation and methods required to bring about a given precipitation retrieval algorithm's optimal performance.

\subsection{Precipitation algorithm opportunities with MTG}

Soon after the advent of the GPM era, the first pair of Meteosat Third Generation (MTG) GEO satellites are now anticipated for launch in the 2017-2019 time frame. By this point, the CDRD and PNPR algorithms will have been flourishing within the H-SAF program (or its next generation follow-up). MTG satellites will use 3-axis stabilization instead of spin stabilization, as is being used with the Meteosat First Generation (MFG) and MSG platforms, with the advantage that the MTGs' onboard instruments will point to the Earth $100 \%$ of the time with longer dwell times. This feature is now considered necessary for a sounding instrument, which the MTG-S sounder platforms will carry (although sounders have been flown on spin-stabilized GOES satellites in the past). MTG satellites will continue to carry imaging instruments, the socalled Flexible Combined Imager (FCI) on dedicated imaging platforms (MTG-I), which will provide solar and infrared observations in 16 channels (5 visible, 3 near-infrared at 1 $\mathrm{km}$ resolution, and 8 infrared at $2-\mathrm{km}$ resolution, in which these channels have allocated at $2 \mathrm{H}_{2} \mathrm{O}, 1 \mathrm{O}_{3}, 1 \mathrm{CO}_{2}$ and 4 window frequencies). All of these measurements will have better spatial, temporal and radiometric resolutions, compared to the predecessor measurements on MFG/MSG satellites. The FCI will image in two modes, a Full-Disk-Scan (FDS) mode with a 10-min repetition cycle, and a European Regional-Rapid-Scan (RRS) mode, which will scan $1 / 4$ of the full disk with a repetition cycle of $2.5 \mathrm{~min}$. In RSS mode, two solar channels provide measurements at $0.5-\mathrm{km}$ resolution while two infrared channels provide measurements at $1-\mathrm{km}$ resolution.

MTG-S platforms will carry the Infrared Sounder (IRS), an interferometer with hyper-spectral resolution in the thermal spectrum, and the high resolution Sentinel-4 Ultraviolet Visible Near-infrared (UVN) spectrometer. Both MTG-I and MTG-S platforms will also carry the Lightning Imager (LI) instrument, which will measure total lightning over the entire observed hemisphere containing the European and African continents. These instruments will be in direct synergy to the Geostationary Lightning Mapper (GLM) instruments to be flown on the next generation GOES-R and GOES-S satellites. As noted, one of the short-term goals for improving the CDRD and PNPR algorithms is to incorporate lightning in- formation into the simulation databases, support that will be provided by LI and GLM measurements.

However, the most important aspect of the new MTG satellite will be the high spatiotemporal resolution FCI measurements and their capacity to make higher quality and better accuracy information on clouds and cloud processes near the cloud tops. The MTG measurements will be used to acquire parameters concerning cloud cover, cloud-top height, shortwave and longwave spectrum optical depths, cloud-top bulk microphysics concentrations and additional details concerning aerosol contents. With the advent of these new retrieval capabilities, and considering the possibilities for using these measurements with the CDRD and PNPR algorithms, three levels of improvement can be anticipated. To assess these three issues, it is necessary to recognize that the CDRD and PNPR algorithms are divided into three different data components (setting aside their distinct algorithm solvers): (I) meteorological observations from operational global forecast models; (II) satellite PMW satellite observations from conical and cross-track scanning radiometers; and (III) simulated PMW observations residing in the algorithms' databases.

Within this framework, the greatest advantages that could be provided by future MTG measurements, over and above current geostationary measurements, will come from the higher quality and more accurate observations of cloud properties,. Used carefully, these cloud parameters could possibly: (1) provide direct observations within the component I parts of the algorithms, i.e., additional meteorological cloud parameters with which to constrain possible algorithm solutions from the simulation database, (2) provide additional sensor data within the component II parts of the algorithms, i.e., additional sensor cloud measurement leverage concerning direct top-of-atmosphere information that would be simulated in parallel with the algorithms' underlying RMS, and (3) provide direct data insertions within the component III parts of the algorithms, i.e., additional microphysical properties outside of what could be simulated by the CRM, which in turn, could be incorporated into RMS calculations of PMW TBs. Obviously research will have to be carried out concerning these possible uses of MTG data for improving the CDRD and PNPR algorithms' methodologies, but given the anticipated quality of the cloud parameters, the future bodes well for improvement.

\section{Conclusions}

Three conclusions deserve mention. First, the ISAC-Rome CDRD and PNPR algorithms were developed over a period of years that required the coming together of the EuroTRMM, EURAINSAT and H-SAF programs in sequence. A period of maturation was required because in seeking accurate and precision algorithms, many solutions to physics problems and model simulations are needed. Thus, a great 
deal of research and testing was required before stable algorithms could be produced. Second, the CDRD algorithm is gradually emerging as a secondary calibration reference for the set of H-SAF precipitation algorithms, partly because it uses the best possible PMW measurements coming from the conically scanning radiometers without contamination from lesser measurements, and partly because of preliminary intercomparisons to the TRMM PR algorithm over the southern portion of the European/Mediterranean Basin region, a region for which the algorithm is relevant. Specifically, a comparison of retrieval results against the TRMM PMW facility algorithm indicates performance behavior on par with or better than the 2a12-v7 counterpart. This is a significant step forward for the H-SAF program. Third, it is apparent that in addition to a number of near-term improvements that will be made, but are not expected to greatly improve the CDRD and PNPR algorithms' accuracies and precisions, the GPM era will offer a number of avenues for improvement that are anticipated to be significant.

\section{Appendix A}

\section{Low-end frequency precipitation screening procedure}

There are two kinds of screening tests that are invoked for the two retrieval algorithms. The first is a "quality-control" test aimed at rejecting telemetry errors that result in nonphysical antenna temperatures. For this, a check is carried out on the brightness temperatures. Any pixels out of reasonable physical limits (i.e., 50-310 K) are rejected. The second is a "detection-of-rainfall" test, and may or may not be linked to the type of surface involved (water, land or coast), depending on which type of channel frequency $(v)$ set is being used; low-end channel frequency screening (available $v$ range between $\sim 18$ and $\sim 95 \mathrm{GHz}$ ) requires knowledge of the type of surface within view whereas high-end channel frequency screening (available $v$ range between $\sim 150$ and $\sim 183 \mathrm{GHz}$ ) does not require such knowledge.

\section{A1 Screening using low-end frequencies (available $v$ range between $\sim 18-95 \mathrm{GHz}$ )}

Detection-of-rainfall screening can involve emission-based tests, scattering-based tests, or both. For low-end screening over water, which has a relatively low and invariant emissivity, screening is not complex and an emission-based test using the lower frequencies of the low-end frequency set are used to determine if rainfall is present in the atmospheric column. For land, surface emissivities are much more variable and generally larger, all of which tends to obscure the emission signature of the water content in an atmospheric column - which is directly related to rainfall - creating a more complex screening process. Over coasts, a measurement involves a mixture of a radiometrically cold water surface and a radiometrically warm land surface, producing even more complexities than associated with land. In essence, rainfall screening for either land or coastal surfaces is designed to detect TB depressions due to scattering in the upper portions of the clouds, requiring use of the higher frequencies within the low-end frequency set in conjunction with a mix of emissionand scattering-based tests.

\section{A1.1 Screening over water}

A water surface's emissivity is generally between $0.4-0.5$. Thus, any precipitation over water generally augments the total radiation stream by emission and thus rain appears warm against a cold background. Each channel frequency responds differently to cloud liquid water depending on the droplet size. An $18-19 \mathrm{GHz}$ channel frequency is the most responsive direct measurement of columnar liquid water for rainbearing clouds; that is, its response generally will not saturate for typical satellite spatial resolutions (see Grody, 1993), that is until the rainfall becomes very intense and the drops become very large or the resolution becomes very small. By the same token, a $37 \mathrm{GHz}$ channel frequency is more sensitive to nonprecipitating clouds with a smaller drop sizes. For low-lying thin stratus clouds with the least amount of liquid water, an $85-90 \mathrm{GHz}$ channel offers the highest sensitivity; it is, however, strongly affected by scattering from precipitation sized ice particles (Weng et al., 1977).

Assuming a channel frequency set for the SSM/I or TMI radiometers (see Table 3), and noting that similar frequencies for the AMSR-E radiometer are effectively interchangeable with their proximate SSM/I or TMI counterparts, the starting point for screening over water is to test if the LWP is above a threshold, which depends on the estimated freezing level height $\left(\mathrm{H}_{\mathrm{FL}}\right)$. The LWP estimate depends on $\log _{10}$ transformations of the $\mathrm{TB}_{22 \mathrm{~V}}$ and $\mathrm{TB}_{37 \mathrm{~V}}$ measurements, modifying an emission-based approach originally suggested by Weng and Grody (1994). If the initial test indicates a sufficiently large LWP, further screens are necessary to eliminate the possibility of a rain-free path in the presence of strong surface winds, surface ice, a clear ocean beneath a dry atmosphere, or finally the possibility of an ambiguity (see Sanò, 2010). The complete screening procedure is described in Fig. A1a.

\section{A1.2 Screening over land}

As noted, the complexity in detecting the presence of rainfall over land is due to the large and variable emissivity of the surface, with dependence on the type of surface, e.g., vegetation, snow, ice, desert, semi-arid soil, etc. Typically, these surfaces exhibit relatively large emissivities, ranging from 0.6 to 0.95 depending on their water content (see Grody, 1988). Such elevated emissivities tend to obscure emission signatures stemming from liquid water in the atmospheric column, consequently requiring the use of scattering-based tests for the detection of rainfall. 


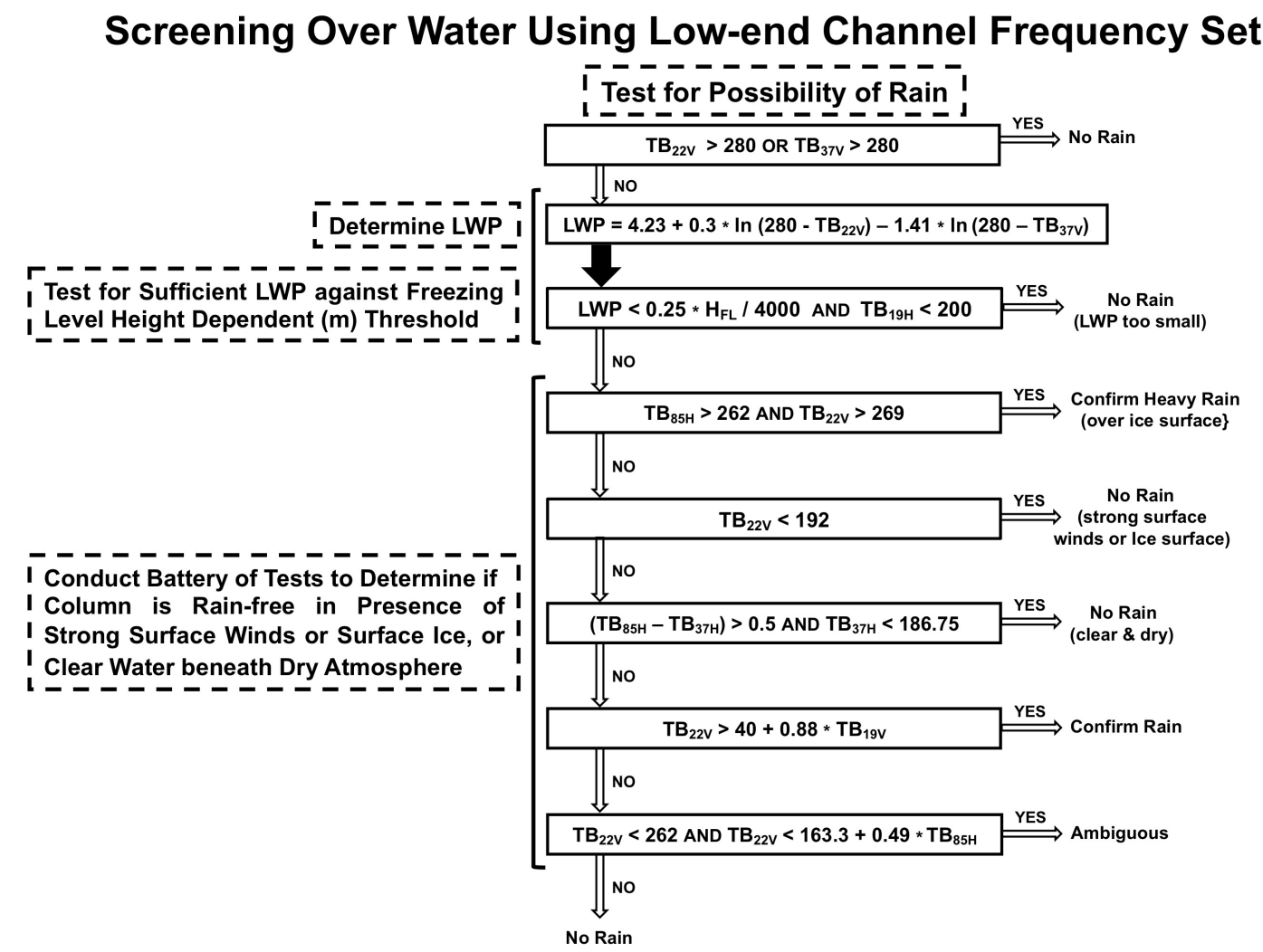

Fig. A1a. Over-water screening procedure for low-end channel frequency set. (Ambiguous denotes "high probability of rain" for data assimilation purposes).

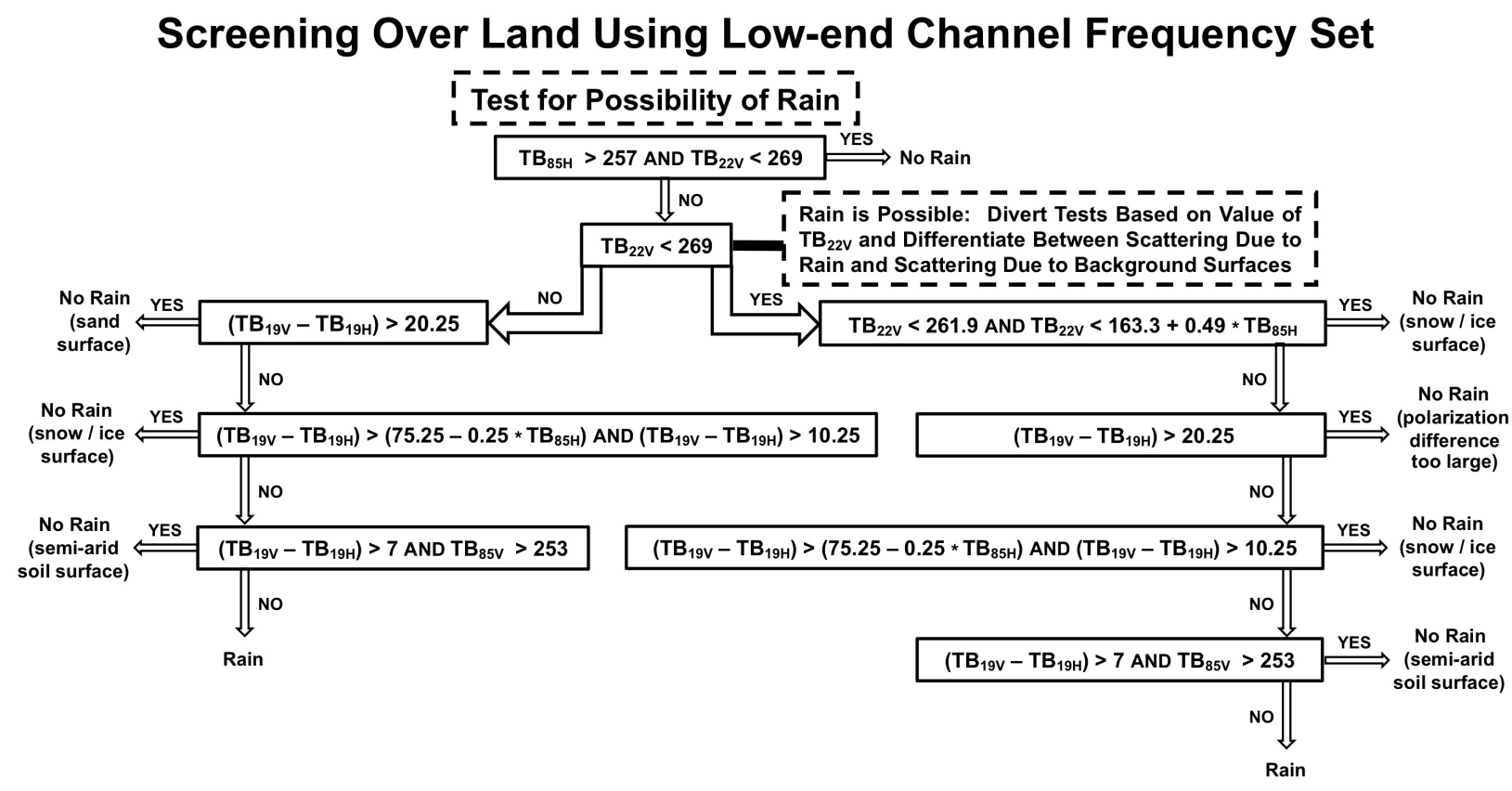

Fig. A1b. Same as (a) except for over land. 


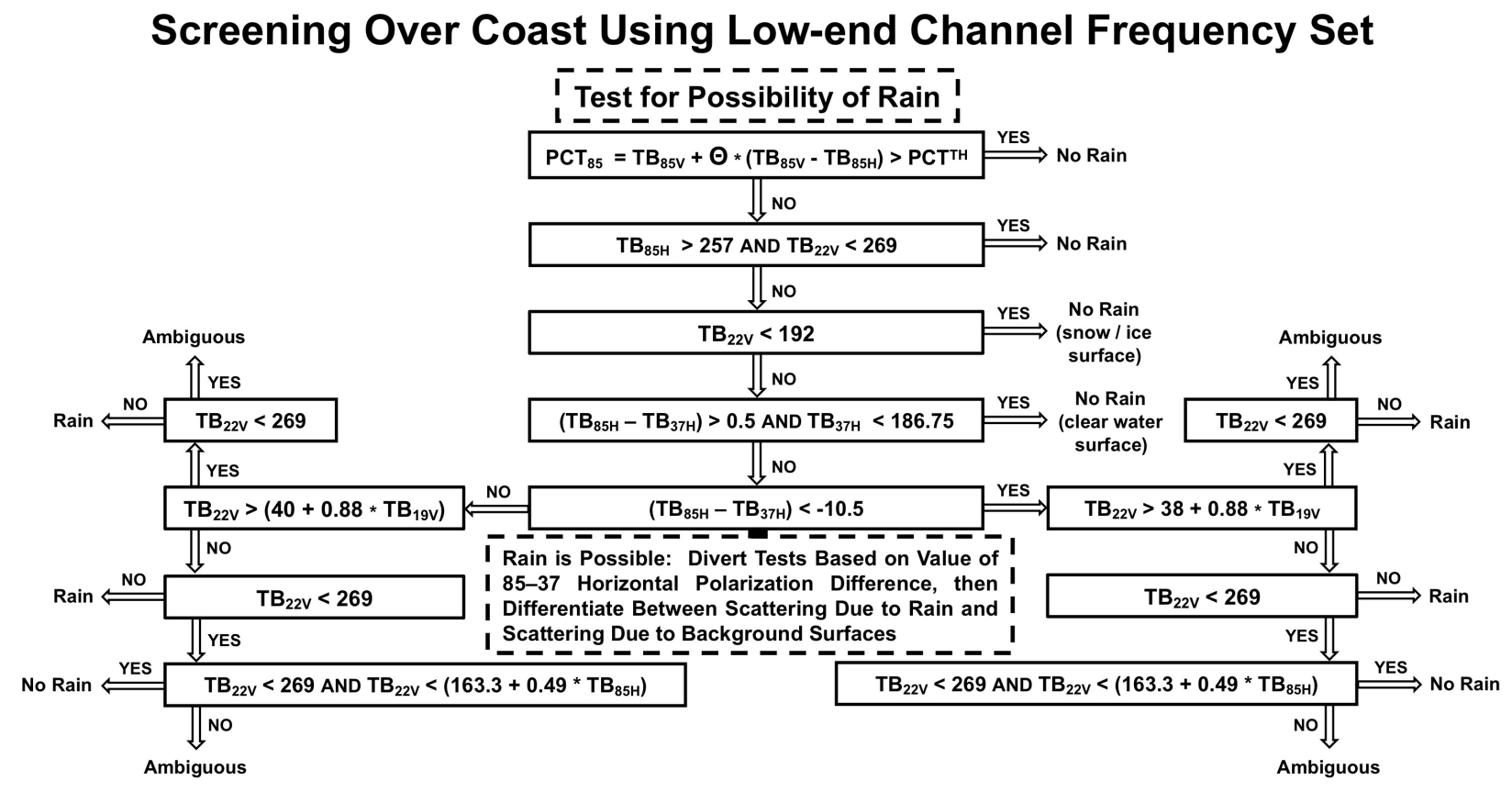

Fig. A1c. Same as (a) except for over coast.

Notably, TBs at a given polarization or vertical-horizontal (V-H) TB polarization differences are dependent on channel frequency and surface type. In general, the scattering signature of rain is identified by a decrease in the V-polarized TB with an increase in frequency, although a snow surface may also indicate this property. Alternatively, for most surfaces, V-H TB polarization differences are greater at lower than at higher frequencies, whereas precipitation exhibits a somewhat flat $\mathrm{V}-\mathrm{H}$ TB polarization difference with respect to frequency. Desert surfaces generally indicate the greatest $\mathrm{V}-\mathrm{H}$ TB polarization differences when considering all land surfaces, although certain snow surfaces can exhibit such large differences.

It is important to recognize that the use of a single $\mathrm{V}$ - or $\mathrm{H}$-polarized TB at a fixed frequency or a single V-H TB polarization difference at a fixed frequency cannot identify the rain signature, given the variety of surface types with their varied behaviours of these quantities. In essence, two tests are necessary; (1) the possible detection of the scattering signature of rain and (2) the confirmation of its existence over different scattering surfaces. Drawing from a body of literature that has addressed this issue over land (see Neale et al., 1990; Grody, 1991; Hollinger, 1991; Ferraro et al., 1994a, b, 1998; Kniveton et al., 1994; Grody and Basist, 1996), a number of scattering-based tests including frequency-dependent $\mathrm{V}$ - and $\mathrm{H}$-polarized TB and V-H TB polarization difference tests are used to differentiate when rain is present or whether a scattering surface itself is giving rise to the scattering sig- nature (see Sanò, 2010). The complete screening procedure is described in Fig. A1b.

\section{A1.3 Screening over coast}

Rainfall screening over coasts is an important component of the overall process because coastal zones contribute a great deal of rainfall by virtue of land-water differential heating, on-shore frictional driven convergence and sea breezes. Because coastal measurement footprints represent a mixture of radiometrically cold water surfaces and radiometrically warm land surfaces, the associated screening schemes are, by nature, more complex than for either surface independently. The main problem originates from the fact that by combining opposite surfaces, a result is generated akin to adding the effects of rainfall whether rainfall is present or not. In essence, when land is in a footprint, the combining of surface water reduces the TB similar to how rainfall scattering creates a TB depression. Alternatively, when surface water is in a footprint, the combining of land increases the TB, similar to how rainfall emission creates a TB warming. Thus, detecting the presence of rain can involve ambiguities without a carefully designed sequence of emission-based and scattering-based tests.

Carefully weighing a number of principles laid out in a body of literature that has addressed coastal screening (see Ulaby et al., 1986; Adler et al., 1993; Ferraro, 1997; Kidd, 1998; Smith et al., 1998; Bennartz, 1999), and using the $85 \mathrm{GHz}$ polarization corrected temperature (PCT) technique developed by Spencer et al. (1989), along with a battery 
of emission/scattering-based tests and frequency-dependent $\mathrm{V}$ - and $\mathrm{H}$-polarized TB and $\mathrm{V}-\mathrm{H}$ TB polarization difference tests, it is possible to effectively differentiate rainfall from a mixed surface signature. The complete screening procedure is described in Fig. A1c.

It is noted in this figure that the $\Theta$ and $\mathrm{PCT}^{\mathrm{TH}}$ parameters, used in conjunction with the $85 \mathrm{GHz}$ PCT test, are seasonally dependent constants. The $\mathrm{PCT}^{\mathrm{TH}}$ is essentially a no rain/rain threshold for the PCT with $\Theta$ (also dependent on the no rain/rain threshold in which $\Theta$ increases as the threshold increases) governing how much polarization is added to the $\mathrm{TB}_{85 \mathrm{~V}}$ value, with the required range of $\Theta$ between 0 and 1. Note that as $\Theta$ increases, pixels with low $\mathrm{TB}_{85 \mathrm{v}} \mathrm{s}$ but high polarization (such as water) will exhibit increasing PCTs at a greater rate than pixels with high $\mathrm{TB}_{85 \mathrm{~V}}$ s but low polarization (such as land surfaces). Therefore, a point is reached where the PCTs of the low $\mathrm{TB}_{85 \mathrm{v}} /$ high polarization pixels exceed the PCTs of the high $\mathrm{TB}_{85 \mathrm{~V}} /$ low polarization pixels. Since rain appears at lower PCT values due to the scattering of the upwelling radiation stream, it is critical that the $\Theta$ and $\mathrm{PCT}^{\mathrm{TH}}$ parameters are sensitive to the value where the PCTs divide between no rain and rain, and the degree to which polarization is allowed to contribute in differentiating between rain and a coastal background. The physical background to this procedure is described in Sanò (2010).

\section{A2 Screening using high-end frequencies (available $v$ range between $\sim 150-183 \mathrm{GHz}$ )}

The high-end frequency screening procedure follows the algorithm of Chen and Staelin (2003), which they developed for the AMSU-A/MHS and/AMSU-B radiometers. For the CDRD algorithm, this procedure is adapted for applications with the SSMIS radiometer whereas for the PNPR algorithm, it is adapted for applications with the AMSU-A/MHS radiometer. This process requires taking into account differences in IFOV scales and polarizations of the $53.6 \mathrm{H} \mathrm{GHz}$, $183 \pm 3 \mathrm{H}$ and $183 \pm 7 \mathrm{H} \mathrm{GHz}$ channels related to differences between the designs of the SSMIS and AMSU-A/MHS instruments. These differences are addressed by calibrating the observed SSMIS TBs involved in the screening procedure to the observed AMSU TBs, taking into account the different spatial resolution of the two sensors.

To start, any $\mathrm{TB}_{183 \pm 7 \mathrm{H}}$ less than the threshold $\mathrm{TB}_{183 \pm 7 \mathrm{H}}^{\mathrm{TH}}=0.667\left(\mathrm{~TB}_{\sim 53 \mathrm{H}}^{\max }-248\right)-252+6 \cos (\theta)$, has its associated microphysical information packet flagged as potentially precipitating, where in the threshold expression $\mathrm{TB}_{\sim 53 \mathrm{H}}^{\max }$ is obtained in two different ways insofar as the PNPR and CDRD screening procedures. For PNPR, $\mathrm{TB}_{\sim 53 \mathrm{H}}^{\max }$, is a spatially filtered $53.6 \mathrm{H} \mathrm{GHz}$ AMSU-A TB $\left(\mathrm{TB}_{53.6 \mathrm{H}}\right)$ found by selecting the warmest $\mathrm{TB}$ value from within a $7 \times 7$ centered grid of a given array of measurements. For CDRD, it is the warmest TB (also from a $7 \times 7$ centered grid) associated with the calibrated $52.3 \mathrm{H} \mathrm{GHz}$ SSMIS channel $\left(\mathrm{TB}_{52.3 \mathrm{Hcal}}\right)$. The function used to ob- tain a calibrated $\mathrm{TB}_{52.3 \mathrm{Hcal}}$ value allied with the most probable $\mathrm{TB}_{53.6 \mathrm{H}}$ value is based on a linear correlation analysis between near-coincident AMSU-A and SSMIS measurements (near in space and within $30 \mathrm{~min}$ ), and is given by $\mathrm{TB}_{52.3 \mathrm{Hcal}}=38.68+0.835 \times \mathrm{TB}_{52.3 \mathrm{H}}$. In case the observed scene corresponds to a very dry and cold atmosphere and the $\mathrm{TB}_{183 \pm 7 \mathrm{H}}$ value might be degraded by contamination from surface emissivity, a 2 nd check needs to be conducted, first testing if a second near- $183 \mathrm{H} \mathrm{GHz}$ frequency $\left(\mathrm{TB}_{183 \pm 3 \mathrm{H}}\right)$ is less than another threshold given by $\mathrm{TB}_{183 \pm 3 \mathrm{H}}^{\mathrm{TH}}=242.5+5 \cos (\theta)$. If so, then the information packet is flagged as potentially precipitating if the $\mathrm{TB}_{53.6 \mathrm{H}}$ values of AMSU-A (or the TB $52.3 \mathrm{Hcal}$ values of SMMIS) are less than $248 \mathrm{~K}$. If this test is positive, a third check is required to determine if the same $\mathrm{TB}$ values are less than $242 \mathrm{~K}$. A resultant positive test here means rejecting the possibility of precipitation.

Acknowledgements. A. Mugnai, D. Casella, S. Dietrich, F. Di Paola, G. Panegrossi and P. Sanò have been supported by a group of six European research programmes: (1) EUMETSAT through the project "Satellite Application Facility on Support to Operational Hydrology and Water Management" (H-SAF); (2) by the European Commission Sixth Framework Programme through the project "Observation, Analysis and Modeling of Lightning Activity in Thunderstorms, for use in Short Term Forecasting of Flash Floods" (FLASH); (3) by the European Community Initiative INTERREG III-B ARCHIMED through the project "Weather Risk Reduction in the Central and Eastern Mediterranean" (RISKMED); (4) by the Italian Civil Protection Department (DPC) through the Operative Agreement DPC-ISAC; (5) by the Italian FISR-MIUR Programme "Sustainable Development and Climate Changes" through the project "Aerosol Effects on Clouds and Climate" (AEROCLOUDS); and (6) by the Italian Space Agency (ASI) through the pilot project "Civil Protection from Floods: The Nowcasting". E. A. Smith and G. J. Tripoli have been supported through NASA's TRMM-GPM science program. B. Bizzarri has been supported by EUMETSAT during the H-SAF development phase.

Edited by: G. Boni

Reviewed by: two anonymous referees

\section{References}

Adler, R. F., Negri, A. J., Keehn, P. R., and Hakkarinen, I. M.: Estimation of monthly rainfall over Japan and surrounding waters from a combination of low-orbit microwave and geosynchronous IR data, J. Appl. Meteor., 32, 335-356, 1993.

AMSU-A: Advanced Microwave Sounding Unit-A (AMSU-A), in: NOAA KLM User's Guide, Section 3.3, NOAA National Environmental Satellite, Data, and Information Service, National Climatic Data Center, available at: http://www.ncdc.noaa.gov/oa/ pod-guide/ncdc/docs/klm/cover.htm, 2009.

Bauer, P., Khain, A., Pokrovsky, A., Meneghini, R., Kummerow, C., Marzano, F., and Poiares Baptista, J. P.: Combined cloud- 
microwave radiative transfer modeling of stratiform rainfall, $\mathrm{J}$. Atmos. Sci., 57, 1082-1104, 2000.

Bauer, P., Amayenc, P., Kummerow, C. D., and Smith, E. A.: Overocean rainfall retrieval from multisensor data of the Tropical Rainfall Measuring Mission, Part II: Algorithm implementation, J. Atmos. Ocean. Technol., 18, 1838-1855, 2001.

Bauer, P., Moreau, E., and Di Michele, S.: Hydrometeor retrieval accuracy from microwave window and sounding channel observations, J. Appl. Meteor., 44, 1016-1032, 2005.

Bennartz, R.: On the use of SSM/I measurements in coastal regions, J. Atmos. Ocean. Technol., 16, 417-431, 1999.

Bennartz, R.: Optimal convolution of AMSU-B to AMSU-A, J. Atmos. Ocean. Technol., 17, 1215-1225, 2000.

Bidwell, S. W., Flaming, G. M., Durning, J. F., and Smith, E. A.: The Global Precipitation Measurement (GPM) Microwave Imager (GMI) instrument: Role, performance, and status, in: Proceedings of the International Geoscience and Remote Sensing Symposium, Seoul, Korea, 25-29 July 2005, 4 pp., doi:10.1109/IGARSS.2005.1526109, 2005.

Bizzarri, B., De Leonibus, L., Jann, A., Wagner, W., Bougeault, P., Pylkko, P., Koskinen, J., Sayin, A., Struzik P., and Grandell, J.: Requirements and plan for a EUMETSAT Satellite Application Facility on support to operational hydrology and water management (H-SAF), Geophys. Res. Abstr., 7, 05316-05317, 2005.

Bizzarri, B. (on behalf of members of H-SAF Consortium): Update on the status of precipitation products in the EUMETSAT Satellite Application Facility on Hydrology and Water Management (H-SAF), in: Proceedings of the 4th IPWG Workshop, Beijing, China, 13-17 October 2008, 45-51, 2008.

Casella, D.: Analysis and Verification of the Cloud Dynamics and Radiation Database (CDRD) Method for the Bayesian Estimation of Precipitation by Means of Satellite-borne Microwave Radiometers, Ph.D. Dissertation, Department of Science, Technical Information and Communication, University of Rome "La Sapienza", Rome, Italy, 121 pp., 2010.

Casella, D., Dietrich, S., Formenton, M., Mugnai, A., Panegrossi, G., Sanò, P., Smith, E. A., and Tripoli, G. J: Verification of Cloud Dynamics and Radiation Database (CDRD) passive microwave precipitation retrieval algorithm using TRMM satellite radar and radiometer measurements over southern Mediterranean basin, in: Extended Abstract Volume of the 12th Specialist Meeting on Microwave Radiometry and Remote Sensing of the Environment, Rome, Italy, 5-9 March 2012, 4 pp., 2012.

Casella, D., Panegrossi, G., Sanò, P., Mugnai, A., Smith, E. A., Tripoli, G. J., Dietrich, S., Formenton, M., Di Paola, F., Leung, H. W.-Y., and Mehta, A. V.: Transitioning from CRD to CDRD in Bayesian retrieval of rainfall from satellite passive microwave measurements, Part 2: Overcoming database profile selection ambiguity by consideration of meteorological control on microphysics, IEEE Trans. Geosci. Remote Sens., in press, 2013.

Chen, F. W. and Staelin, D. H.: AIRS/AMSU/HSB precipitation estimates, IEEE Trans. Geosci. Remote Sens., 41, 410-417, 2003.

Di Michele, S., Marzano, F. K., Mugnai, A., Tassa, A., and Poiares Baptista, J. P. V.: Physically based statistical integration of TRMM microwave measurements for precipitation profiling, Radio Sci., 38, 8072, doi:10.1029/2002RS002636, 2003.

Di Michele, S., Tassa, A., Mugnai, A., Marzano, F. K., Bauer, P., and Poiares Baptista, J. P. V.: Bayesian algorithm for microwavebased precipitation retrieval: Description and application to TMI measurements over ocean, IEEE Trans. Geosci. Rem. Sens., 43, 778-791, 2005.

Dudhia, J.: A nonhydrostatic version of the Penn State-NCAR Mesoscale Model: Validation tests and simulation of an Atlantic cyclone and cold front, Mon. Weather Rev., 121, 1493-1513, 1993.

ECMWF: Assimilation of Clouds and Precipitation: Retrieval Algorithms, Proceedings of the ECMWF/EuroTRMM Workshop, European Centre for Medium-Range Weather Forecasts, Shinfield Park, Reading, United Kingdom, 20 November 2000, 257354, 2001.

Ebert, E. E., Janowiak, J. E., and Kidd, C.: Comparison of nearreal-time precipitation estimates from satellite observations and numerical models, Bull. Am. Meteor. Soc., 88, 47-64, 2007.

Evans, K. F., Turk, J., Wong, T., and Stephens, G. L.: A Bayesian approach to microwave precipitation profile retrieval, J. Appl. Meteor., 34, 260-279, 1995.

Farrar, M. R.: Combined Radar-Radiometer Rainfall Retrieval for TRMM Using Structure Function-based Optimization, Ph.D. Dissertation (E.A. Smith, Major Prof.), Department of Meteorology, The Florida State University, Tallahassee, Florida, USA, 185 pp., 1997.

Ferraro, R. R.: Special Sensor Microwave Imager derived global rainfall estimates for climatological applications, J. Geophys. Res., 102, 16715-16735, 1997.

Ferraro, R. R., Grody, N. C., Forsyth, D., Carey, R., Basist, A., Janowiak, J., Weng, F., Marks, G., and Yanamandra, R.: Microwave measurements produce global climatic, hydrologic data, EOS Trans. Amer. Geophys. Union, 75, 337-343, 1994a.

Ferraro, R. R., Grody, N. C., and Marks, G. F.: Effects of surface conditions on rain identification using the SSM/I, Remote Sens. Rev., 11, 195-209, 1994b.

Ferraro, R. R., Smith, E. A., Berg, W., and Huffman, G. J.: A review of screening techniques for passive microwave precipitation retrieval algorithms, J. Atmos. Sci., 55, 1583-1600, 1998.

Formenton, M., Panegrossi, G., Casella, D., Dietrich, S., Mugnai, A., Sanò, P., Di Paola, F., Betz, H.-D., Price, C., and Yair, Y.: Using a cloud electrification model to study relationships between lightning activity and cloud microphysical structure, Nat. Hazards Earth Syst. Sci. Discuss., in press, 2013.

GMI: NASA Global Precipitation Measurement (GPM) Microwave Imager (GMI) Level 1B (L1B) Algorithm Theoretical Basis Document (ATBD) [version $0.01 \mathrm{draft}$, NASA/Goddard Space Flight Center, Greenbelt, Maryland, USA, 2010.

Goldberg, M. D., Crosby, D. S., and Zhou, L.: The limb adjustment of AMSU-A observations: Methodology and validation, J. Appl. Meteor., 40, 70-83, 2001.

Gorgucci, E. and Baldini, L.: An examination of the validity of the mean raindrop-shape model for dual-polarization radar rainfall retrievals, IEEE Trans. Geosci. Remote Sens., 47, 2752-2761, 2009.

Gorgucci, E., Scarchilli, G., Chandrasekar, V., and Bringi, V. N.: Rainfall estimation from polarimetric radar measurements: composite algorithms immune to variability in raindrop shape-size relation, J. Atmos. Ocean. Technol., 18, 1773-1786, 2001.

Grecu, M., Olson, W. S., and Anagnostou, E. N.: Retrieval of precipitation profiles from multiresolution, multifrequency active and passive microwave observations, J. Appl. Meteor., 43, 562575, 2004. 
Grell, G., Dudhia, J., and Stauffer, D. R.: A Description of the Fifth Generation Penn State/NCAR Mesoscale Model (MM5), NCAR Techical Note NCAR/TN-398+STR, National Center for Atmospheric Research, Boulder, Colorado, USA, 121 pp., 1994.

Grody, N. C.: Surface identification using satellite microwave radiometer, IEEE Trans. Geosci. Remote Sens., 26, 850-859, 1988.

Grody, N. C.: Classification of snow cover and precipitation using the Special Sensor Microwave Imager, J. Geophys. Res., 103, 7423-7435, 1991.

Grody, N. C.: Remote sensing of the atmosphere from satellite using microwave radiometry, in: Atmospheric Remote Sensing by Microwave Radiometry, edited by: Jannsen, M. A., John Wiley and Sons, 259-314, 1993.

Grody, N. C. and Basist, A.: Global identification of snow cover using SSM/I measurements, IEEE Trans. Geosci. Remote Sens., 34, 237-249, 1996.

Grody, N., Weng, F., and Ferraro, R.: Application of AMSU for obtaining hydrological parameters, in: Microwave Radiometry and Remote Sensing of the Earth's Surface and Atmosphere, edited by: Pampaloni, P. and Paloscia, S., VSP 2000, 339-352, 2000.

Grose, A. M. E., Smith, E. A., Chung, H.-S., Ou, M.-L., Sohn, B.J., and Turk, F. J.: Possibilities and limitations for quantitative precipitation forecasts using nowcasting methods with infrared geosynchronous satellite imagery, J. Appl. Meteor., 41, 763-785, 2002.

Haddad, Z. S., Smith, E. A., Kummerow, C. D., Iguchi, T., Farrar, M. R., Durden, S. L., Alves, M., and Olson, W. S.: The TRMM "Day-1" radar/radiometer combined rain-profiling algorithm, J. Meteor. Soc. Jpn, 75, 799-809, 1997.

Haykin, S. O.: Neural Networks: A Comprehensive Foundation, 2nd Edn., Prentice Hall, 842 pp., 1998.

Haykin, S. O.: Neural Networks and Learning Machines, 3rd Edn., Prentice Hall, 906 pp., 2009.

Hollinger, J.: DMSP SSM/I Calibration Validation, Final Report Parts I-II, Naval Research Laboratory, Monterey, California, USA, 419 pp., 1991.

Huffman, G. J, Adler, R. F., Bolvin, D. T., Gu, G., Nelkin, E. J., Bowman, K. P., Hong, Y., Stocker, E. F., and Wolff, D. B.: The TRMM Multisatellite Precipitation Analysis (TMPA): Quasiglobal, multiyear, combined-sensor precipitation estimates at fine scales, J. Hydrometeorol., 8, 38-55, 2007.

Iguchi, T., Kozu, T., Meneghini, R., Awaka, J., and Okamoto, K.: Rain-profiling algorithm for the TRMM Precipitation Radar, J. Appl. Meteor., 39, 2038-2052, 2000.

Iguchi, T., Oki, R., Smith, E. A., and Furuhama, Y.: Global Precipitation Measurement program and the development of dualfrequency precipitation radar, J. Comm. Res. Laboratory, 49, 3745, 2002.

Iguchi, T., Kozu, T., Kwiatkowski, J., Meneghini, R., Awaka, J., and Okamoto, K.: Uncertainties in the rain profiling algorithm for the TRMM Precipitation Radar, J. Meteor. Soc. Japan, 87A, 1-30, 2009.

Joyce, R. J., Janowiak, J. E., Arkin, P. A., and Xie, P.: CMORPH: A method that produces global precipitation estimates from passive microwave and infrared data at high spatial and temporal resolution, J. Hydrometeorol., 5, 487-503, 2004.

Kawanishi, T., Sezai, T., Ito, Y., Imaoka, K., Takeshima, T., Ishido, Y., Shibata, A., Miura, M., Inahata, H., and Spencer, R. W.: The Advanced Microwave Scanning Radiometer for the Earth Ob- serving System (AMSR-E): NASDA's contribution to the EOS for global energy and water cycle studies, IEEE Trans. Geosci. Remote Sens., 41, 184-194, 2003.

Kidd, C.: On rainfall retrieval using polarization-corrected temperatures, J. Remote Sens., 19, 981-996, 1998.

Kidder, S. Q.: Tropical oceanic precipitation frequency from Nimbus 5 microwave data, Atmospheric Science Paper 248, Colorado State University, Fort Collins, Colorado, USA, 50 pp., 1976.

Kniveton, D. R., Motta, B. C., Goodman, H. M., Smith, M., and LaFontaine, F. J.: The first Wetnet precipitation intercomparison project: Generation of results, Remote Sens. Rev., 11, 243-302, 1994.

Kummerow, C., Barnes, W., Kozu, T., Shiue, J., and Simpson, J.: The Tropical Rainfall Measuring Mission (TRMM) sensor package, J. Atmos. Ocean. Technol., 15, 809-817, 1998.

Kummerow, C., Hong, H., Olson, W. S., Yang, S., Adler, R. F., McCollum, J., Ferraro, R., Petty, G., Shin, D.-B., and Wilheit, T. T.: The evolution of the Goddard Profiling Algorithm (GPROF) for rainfall estimation from passive microwave sensors, J. Appl. Meteor., 40, 1801-1820, 2001.

Kummerow, C. D., Ringerud, S., Crook, J., Randel, D., and Berg, W.: An observationally generated a priori database for microwave rainfall retrievals, J. Atmos. Ocean. Technol., 28, 113130, 2011.

Levizzani, V., Porcù, F., Marzano, F. S., Mugnai, A., Smith, E. A., and Prodi, F.: Investigating a SSM/I microwave algorithm to calibrate METEOSAT infrared instantaneous rainrate estimates, Meteorol. Appl., 3, 5-17, 1996.

Levizzani, V., Bauer, P., and Turk, F. J. (Eds.): Measuring Precipitation from Space: EURAINSAT and the Future, Advances in Global Change Research, Volume 28, Springer, Dordrecht, The Netherlands, 748 pp., 2007.

Marzano, F. S., Mugnai, A., Smith, E. A., Xiang, X., Turk, F. J., and Vivekanandan, J.: Active and passive remote sensing of precipitating storms during CaPE, Part II: Intercomparison of precipitation retrievals from AMPR radiometer and CP-2 radar, Meteorol. Atmos. Phys., 54, 29-51, 1994.

Marzano, F. S., Mugnai, A., Panegrossi, G., Pierdicca, N., Smith, E. A., and Turk, F. J.: Bayesian estimation of precipitating cloud parameters from combined measurements of spaceborne microwave radiometer and radar, IEEE Trans. Geosci. Remote Sens., 37, 596-613, 1999.

Marzano, F. S., Palmacci, M., Cimini, D., Giuliani, G., and Turk, F. J.: Multivariate atatistical integration of satellite infrared and microwave radiometric measurements for rainfall retrieval at the geostationary scale, IEEE Trans. Geosci. Remote Sens., 42, 1018-1032, 2004.

MHS: Microwave Humidity Sounder (MHS), in: NOAA KLM User's Guide, Section 3.9, NOAA National Environmental Satellite, Data, and Information Service, National Climatic Data Center, available at: http://www.ncdc.noaa.gov/oa/pod-guide/ncdc/ docs/klm/cover.htm, 2009.

Mugnai, A., Smith, E. A., and Tripoli, G. J.: Foundations for statistical - physical precipitation retrieval from passive microwave satellite measurements, Part II: Emission source and generalized weighting function properties of a time dependent cloud - radiation model, J. Appl. Meteor., 32, 17-39, 1993.

Mugnai A., Bizzarri, B., Di Paola, F., Dietrich, S., Levizzani, V., and Torricella, F.: Unified framework for precipitation retrieval 
and analysis by means of multisensor satellite observations and cloud model simulations: Application to H-SAF, Proceedings of the EUMETSAT Meteorological Satellite Conference (keynote presentation), Helsinki, Finland, 12-16 June 2006, EUMETSAT P.48, 10 pp., 2006.

Mugnai, A., Di Michele, S., Smith, E. A., Baordo, F., Bauer, P., Bizzarri, B., Joe, P., Kidd, C., Marzano, F. S., Tassa, A., Testud, J., and Tripoli, G. J.: Snowfall measurements by proposed European GPM mission, in: Measuring Precipitation from Space: EURAINSAT and the Future, edited by: Levizzani, V., Bauer, P., and Turk, F. J., Advances in Global Change Research, Volume 28, Springer, Dordrecht, The Netherlands, 655-674, 2007.

Mugnai, A., Smith, E. A., Tripoli, G. J., Dietrich, S., Kotroni, V., Lagouvardos, K., and Medaglia, C. M.: Explaining discrepancies in passive microwave cloud-radiation databases in microphysical context from two different cloud-resolving models, Meteorol. Atmos. Phys., 101, 127-145, doi:10.1007/s00703-007-02814, 2008.

Mugnai, A., Casella, D., Cattani, E., Dietrich, S., Laviola, S., Levizzani, V., Panegrossi, G., Petracca, M., Sanò, P., Di Paola, F., Biron, D., De Leonibus, L., Melfi, D., Rosci, P., Vocino, A., Zauli, F., Puca, S., Rinollo, A., Milani, L., Porcù, F., and Gattari, F.: Precipitation products from the Hydrology SAF, Nat. Hazards Earth Syst. Sci. Discuss., in press, 2013.

Munchak, S. J. and Kummerow, C. D.: A modular optimal estimation method for combined radar-radiometer precipitation profiling, J. Appl. Meteor. Climat., 50, 433-448, 2011.

Nakamura, K., Iguchi, T., Kojima, M., and Smith, E. A.: Global Precipitation Mission (GPM) and Dual-Wavelength Radar (DPR), Proceedings of XXVIII URSI General Assembly, New Delhi, India, 23-29 October 2005, 4 pp., 2005.

Neale, C. M. U., McFarkand, M. J., and Chang, K.: Land surface classification using microwave brightness temperatures from the Special Sensor Microwave/Imager, IEEE Trans. Geosci. Remote Sens., 28, 829-838, 1990.

Newell, D. A., Rait, G., Ta, T., Berdanier, B., Draper, D., Kubitschek, M., and Krimchansky, S.: GPM Microwave Imager design, predicted performance and status, Proceedings of the International Geoscience and Remote Sensing Symposium, Honolulu, Hawaii, USA, 25-30 July 2010, 546-549, doi:10.1109/IGARSS.2010.5652098, 2010.

Panegrossi, G., Dietrich, S., Marzano, F. S., Mugnai, A., Smith, E. A., Xiang, X., Tripoli, G. J., Wang, P. K., and Poiares Baptista, J. P. V.: Use of cloud model microphysics for passive microwave-based precipitation retrieval: Significance of consistency between model and measurement manifolds, J. Atmos. Sci., 55, 1644-1673, 1998.

Pierdicca, N., Marzano, F. S., d'Auria, G., Basili, P., Ciotti, P., and Mugnai, A.: Precipitation retrieval from spaceborne microwave radiometers based on maximum a posteriori probabilità estimation, IEEE Trans. Geosci. Rem. Sens., 34, 831-846, 1996.

Puca, S., Baguis, P., Campione, E., Ertürk, A., Gabellani, S., Iwański, R., Jurašek, M., Kaňák, J., Kerényi, J., Koshinchanov, G., Kozinarova, G., Krahe, P., Łapeta, B., Lábó, E., Milani, L., Okon, O., Öztopal, A., Pagliara, P., Pignone, F., Porcù, F., Rachimow, C., Rebora, N., Rinollo, A., Roulin, E., Sönmez, İ., Toniazzo, A., Vulpiani, G., Biron, D., Casella, D., Cattani, E., Dietrich, S., Laviola, S., Levizzani, V., Melfi, D., Mugnai, A., Panegrossi, G., Petracca, M., Sanò, P., Zauli, F., Rosci, P., and De
Leonibus, L.: The validation service of the Hydrological SAF geostationary and polar satellite precipitation products, Nat. Hazards Earth Syst. Sci. Discuss., in press, 2013.

Prigent, C., Chevallier, F., Karbou, F., Bauer, P., and Kelly, G.: AMSU-A land surface emissivity estimation for numerical weather prediction assimilation schemes, J. Appl. Meteor., 44, 416-426, 2005.

Rosenkranz, P: Rapid radiative transfer model for AMSU/HSB channels, IEEE Trans. Geosci. Rem. Sens., 41, 362-368, 2003.

Sanò, P.: The Cloud Dynamics and Radiation Database (CDRD) Approach for Precipitation Retrieval by Means of Satellite Based Microwave Radiometry, Ph.D. Dissertation, Department of Computer, Systems and Production Engineering, University of Rome "Tor Vergata", Rome, Italy, 165 pp., 2010.

Sanò, P., Casella, D., Mugnai, A., Schiavon, A., Smith, E. A., and Tripoli, G. J.: Transitioning from CRD to CDRD in Bayesian retrieval of rainfall from satellite passive microwave measurements, Part 1: Algorithm description and testing, IEEE Trans. Geosci. Remote Sens., in press, 2013.

Simpson, J., Kummerow, C. D., Tao, W.-K., and Adler, R. F.: On the Tropical Rainfall Measuring Mission (TRMM) satellite, Meteorol. Atmos. Phys., 60, 19-36, 1996.

Smith, E. A., Mugnai, A., Cooper, H. J., Tripoli, G. J., and Xiang, X.: Foundations for statistical - physical precipitation retrieval from passive microwave satellite measurements, Part I: Brightness temperature properties of a time dependent cloud - radiation model, J. Appl. Meteor., 31, 506-531, 1992.

Smith, E. A., Xiang, X., Mugnai, A., and Tripoli, G. J.: Design of an inversion-based precipitation profile retrieval algorithm using an explicit cloud model for initial guess microphysics, Meteorol. Atmos. Phys., 54, 53-78, 1994a.

Smith, E. A., Mugnai, A., and Tripoli, G. J.: Theoretical foundations and verification of a multispectral, inversion-type microwave precipitation profile retrieval algorithm, in: Passive Microwave Remote Sensing of Land-Atmosphere Interactions, edited by: Pampaloni, P., VSP Press, Utrecht, The Netherlands, 599-621, 1994 b.

Smith, E. A., Turk, F. J., Farrar, M., Mugnai, A., and Xiang, X.: Estimating $13.8 \mathrm{GHz}$ path integrated attenuation from $10.7 \mathrm{GHz}$ brightness temperatures for TRMM combined PR-TMI precipitation algorithm, J. Appl. Meteor., 36, 365-388, 1997.

Smith, E. A., Lamm, J., Adler, R., Alishouse, J., Aonashi, K., Barrett, E., Bauer, P., Berg, W., Chang, A., Ferraro, R., Ferriday, J., Goodman, S., Grody, N., Kidd, C., Kniveton, D., Kummerow, C., Liu, G., Marzano, F., Mugnai, A., Olson, W., Petty, G., Shibata, A., Spencer, R., Wentz, F., Wilheit, T., and Zipser, E.: Results of WetNet PIP-2 project, J. Atmos. Sci., 55, 1483-1536, 1998.

Smith, E. A., Bauer, P., Marzano, F. S., Kummerow, C. D., McKague, D., Mugnai, A., and Panegrossi, G.: Intercomparison of microwave radiative transfer models in precipitating clouds, IEEE Trans. Geosci. Remote Sens., 40, 541-549, 2002.

Smith, E. A., Asrar, G., Furuhama, Y., Ginati, A., Mugnai, A., Nakamura, K., Adler, R. F., Chou, M.-D., Desbois, M., Durning, J. F., Einaudi, F., Entin, J. K., Ferraro, R. R., Guzzi, R., Houser, P. R., Hwang, P. H., Iguchi, T., Joe, P., Kakar, R., Kaye, J. A., Kojima, M., Kummerow, C. D., Kuo, K.-S., Lettenmaier, D. P., Levizzani, V., Lu, N., Mehta, A. V., Morales, C., Morel, P., Nakazawa, T., Neeck, S. P., Okamoto, K., Oki, R., Raju, G., Shepherd, J. M., Simpson, J., Sohn, B.-J., Stocker, E. F., Tao, W.-K., Testud, 
J., Tripoli, G. J., Wood, E. F., Yang, S., and Zhang, W.: International Global Precipitation Measurement (GPM) Program and Mission: An overview, in: Measuring Precipitation from Space: EURAINSAT and the Future, edited by: Levizzani, V., Bauer, P., and Turk, F. J., Advances in Global Change Research, Volume 28, Springer, Dordrecht, The Netherlands, 611-653, 2007.

Smith, E. A., Leung, H. W.-L., Elsner, J. B., Mehta, A. V., Tripoli, G. J., Casella, D., Dietrich, S., Mugnai, A., Panegrossi, G., and Sanò, P.: Transitioning from CRD to CDRD in Bayesian retrieval of rainfall from satellite passive microwave measurements, Part 3: Identification of optimal meteorological tags, Nat. Hazards Earth Syst. Sci. Discuss., in press, 2013.

Sorooshian, S., Hsu, K.-L., Gao, X., Gupta, H. V., Imam, B., and Braithwaite, D.: Evaluation of PERSIANN system satellitebased estimates of tropical rainfall, Bull. Amer. Meteor. Soc., 81, 2035-2046, 2000.

Spencer, R. W., Goodman, H. M., and Hood, R. E.: Precipitation retrieval over land and ocean with the SSM/I: Identification and characteristics of the scattering signal, J. Atmos. Ocean. Technol., 6, 254-273, 1989.

SSM/I: Special Sensor Microwave/Imager (SSM/I) User's Interpretation Guide, DMSP Program Office, USAF Space and Missile Systems Center, El Segundo, California, USA, 104 pp., 2000.

SSMIS: Algorithm and Data User Manual (ADUM) for the Special Sensor Microwave Imager/Sounder (SSMIS), Technical Report 12621, Northrop Grumman Corporation, Space Systems Division, Azusa, California, USA, 65 pp., 2002.

Surussavadee, C. and Staelin, D. H.: Global millimeter-wave precipitation retrievals trained with a cloud-resolving numerical weather prediction model, Part I: Retrieval design, IEEE Trans. Geosci. Remote Sens., 46, 99-108, 2008a.

Surussavadee, C. and Staelin, D. H.: Global millimeter-wave precipitation retrievals trained with a cloud-resolving numerical weather prediction model, Part II: Performance evaluation, IEEE Trans. Geosci. Remote Sens., 46, 109-118, 2008 b.

Surussavadee, C. and Staelin, D. H.: Satellite retrievals of Arctic and Equatorial rain and snowfall rates using millimeters wavelengths, IEEE Trans. Geosci. Remote Sens., 47, 3697-3707, 2009.

Tassa, A., Di Michele, S., Mugnai, A., Marzano, F. S., and Poiares Baptista, J. P. V.: Cloud model-based Bayesian technique for precipitation profile retrieval from the Tropical Rainfall Measuring Mission Microwave Imager, Radio Sci., 38, 8074, doi:10.1029/2002RS002674, 2003.

Tassa, A., Di Michele, S., Mugnai, A., Marzano, F. S., Bauer, P., and Poiares Baptista, J. P. V.: Modeling uncertainties for passive microwave precipitation retrieval: Evaluation of a case study, IEEE Trans. Geosci. Rem. Sens., 44, 78-89, 2006.
Torricella, F., Levizzani, V., and Turk, F. J.: Application of a blended MW-IR rainfall algorithm to the Mediterranean, in: Measuring Precipitation from Space: EURAINSAT and the Future, edited by: Levizzani, V., Bauer, P., and Turk, F. J., Advances in Global Change Research, Volume 28, Springer, Dordrecht, The Netherlands, 497-508, 2007.

Tripoli, G. J.: A nonhydrostatic model designed to simulate scale interaction, Mon. Weather Rev., 120, 1342-1359, 1992.

Tripoli, G. J. and Smith, E. A.: Introducing variable-step topography (VST) coordinates within dynamically constrained Nonhydrostatic Modeling System (NMS), Part 1: VST formulation within NMS host model framework, Dyn. Atmos. Oceans, submitted, 2013a.

Tripoli, G. J. and Smith, E. A.: Introducing variable-step topography (VST) coordinates within dynamically constrained Nonhydrostatic Modeling System (NMS), Part 2: VST performance on orthodox obstacle flows, Dyn. Atmos. Oceans, submitted, 2013b.

Turk, F. J. and Miller, S. D.: Toward improving estimates of remotely-sensed precipitation with MODIS/AMSR-E blended data techniques, IEEE Trans. Geosci. Remote Sens., 43, 10591069, 2005.

Turk, F. J., Rohaly, G. D., Hawkins, J., Smith, E. A., Marzano, F. S., Mugnai, A., and Levizzani, V.: Meteorological applications of precipitation estimation from combined SSM/I, TRMM and infrared geostationary satellite data, in: Microwave Radiometery and Remote Sensing of the Earth's Surface and Atmosphere, edited by: Pampaloni, P. and Paloscia, S., VSP Press, Utrecht, The Netherlands, 353-363, 1999.

Ulaby, F. T., Moore, R. K., and Fung, A. K.: Microwave Remote Sensing: Active and Passive, Vol. III: Volume Scattering and Emission Theory, Advanced Systems and Applications, Artech House Inc., Dedham, Massachusetts, USA, 1100 pp., 1986.

Weng, F. and Grody, N. C.: Retrieval of cloud liquid water using the Special Sensor Microwave/Imager (SSM/I), J. Geophys. Res., 99, 25535-25551, 1994.

Weng, F., Grody, N. C., Ferraro, R. R., Basist, A., and Forsyth, D.: Cloud liquid water climatology from Special Sensor Microwave/Imager, J. Climate, 10, 1086-1098, 1997.

Wilheit, T. T.: The Electrically Scanning Microwave Radiometer (ESMR), in: The Nimbus 5 User's Guide, NASA/Goddard Space Flight Center, Greenbelt, Maryland, USA, 55-105, 1972.

Wimmers, A. J. and Velden, C. J.: A new approach to visualizing satellite microwave imagery of tropical cyclones, Bull. Amer. Meteor. Soc., 88, 1187-1196, 2007. 